This item was submitted to Loughborough's Research Repository by the author.

Items in Figshare are protected by copyright, with all rights reserved, unless otherwise indicated.

\title{
Interlaboratory comparison of angular-dependent photovoltaic device measurements: Results and impact on energy rating
}

\section{PLEASE CITE THE PUBLISHED VERSION}

https://doi.org/10.1002/pip.3365

\section{PUBLISHER}

Wiley

\section{VERSION}

AM (Accepted Manuscript)

\section{PUBLISHER STATEMENT}

This is the peer reviewed version of the following article: Riedel-Lyngskær, N. ... et al., (2021). Interlaboratory comparison of angular-dependent photovoltaic device measurements: Results and impact on energy rating. Progress in Photovoltaics: Research and Applications, 29(3_, pp. 315-333, which has been published in final form at https://doi.org/10.1002/pip.3365. This article may be used for non-commercial purposes in accordance with Wiley Terms and Conditions for Use of Self-Archived Versions

\section{LICENCE}

CC BY-NC-ND 4.0

\section{REPOSITORY RECORD}

Riedel-Lyngskær, N, AA Santamaría Lancia, F Plag, I Kröger, MR Vogt, C Schinke, RS Davidsen, et al.. 2020. "Interlaboratory Comparison of Angular-dependent Photovoltaic Device Measurements: Results and Impact on Energy Rating". Loughborough University. https://hdl.handle.net/2134/14248619.v1. 


\section{Interlaboratory comparison of angular-dependent photovoltaic device measurements: Results and} impact on energy rating

Nicholas Riedel-Lyngskær ${ }^{1}$, Adrián A. Santamaría Lancia ${ }^{1}$, Fabian Plag ${ }^{2}$, Ingo Kröger ${ }^{2}$, Malte R. Vogt ${ }^{3}$, Carsten Schinke ${ }^{3,4}$, Rasmus S. Davidsen ${ }^{5}$, Mekbib Amdemeskel ${ }^{1}$, Mark J. Jansen ${ }^{6}$, Petra Manshanden ${ }^{6}$, Lenneke H. Slooff ${ }^{6}$, Anna J. Carr ${ }^{6}$, Martin Bliss ${ }^{7}$, Tom Betts ${ }^{7}$, Mikel E. Mayo ${ }^{8}$, Iñigo P. Jauregui ${ }^{8}$, Jose L. Balenzategui ${ }^{9}$, Ruben Roldan ${ }^{10}$, Giovanni Bellenda ${ }^{10}$, Mauro Caccivio ${ }^{10}$, Ulli Kräling ${ }^{11}$, Frank Neuberger ${ }^{11}$, Daniel Zirzow ${ }^{12}$, Jim Crimmins ${ }^{12}$, Charles Robinson ${ }^{13}$, Bruce King ${ }^{13}$, Wesley Teasdale ${ }^{14}$, Cherif Kedir ${ }^{14}$, John Watts $^{15}$, Ryan Desharnais ${ }^{15}$, Peter B. Poulsen ${ }^{1}$, Michael L. Jakobsen ${ }^{1}$, Gisele A. dos Reis Benatto ${ }^{1}$

1. Technical University of Denmark, Department of Photonics Engineering, 4000 Roskilde, Denmark

2. Physikalisch-Technische Bundesanstalt (PTB), 38116 Braunschweig, Germany

3. Institute for Solar Energy Research Hamelin (ISFH), 31860 Emmerthal, Germany

4. Leibniz University Hanover, Institute for Solid State Physics, Solar Energy Department, 30167 Hannover, Germany

5. Technical University of Denmark, National Centre for Nano Fabrication and Characterization, 2800 Lyngby, Denmark

6. TNO Energy Transition, 1755 LE Petten, the Netherlands

7. Centre for Renewable Energy Systems Technology (CREST), Wolfson School of Mechanical, Electronic and Manufacturing Engineering, Loughborough University, Loughborough, LE11 3TU, UK

8. Spanish National Renewable Energy Centre (CENER), 31621 Sarriguren, Spain

9. PVLab, Photovoltaic Solar Energy Unit, CIEMAT, 28040 Madrid, Spain

10. University of Applied Sciences and Arts of Southern Switzerland, Institute for Applied Sustainability to the Built Environment (SUPSI - ISAAC), Campus Trevano, CH-6952 Canobbio, Switzerland

11. Fraunhofer Institute for Solar Energy Systems ISE, CalLab PV Modules, 79110 Freiburg, Germany

12. CFV Laboratories, Albuquerque, NM, 87110, USA

13. Sandia National Laboratories, Albuquerque, NM, 87185-0951, USA

14. Renewable Energy Test Center (RETC), Fremont, CA, 94538, USA

15. PV Evolution Labs (PVEL), Berkeley, CA, 94710, USA

Corresponding Author: Nicholas Riedel-Lyngskær, nrie@fotonik.dtu.dk, Technical University of Denmark, Department of Photonics Engineering, 4000 Roskilde, Denmark

DOI: https://doi.org/10.1002/pip.3365 


\section{Abstract}

This paper presents the results from an extensive interlaboratory comparison of angular-dependent measurements on encapsulated photovoltaic (PV) cells. Twelve international laboratories measure the incident angle modifier of two unique PV devices. The absolute measurement agreement is $\pm 2.0 \%$ to the weighted mean for angles of incidence $(\mathrm{AOI}) \leq 65^{\circ}$, but from $70^{\circ}-85^{\circ}$ the range of measurement deviations increases rapidly from $2.5 \%-23 \%$. The proficiency of the measurements is analyzed using the expanded uncertainties published by seven of the laboratories, and it is found that most of the angular-dependent measurements are reproducible for $\mathrm{AOI} \leq 80^{\circ}$. However, at $85^{\circ}$ one laboratory's measurements do not agree to the weighted mean within the stated uncertainty, and measurement uncertainty as high as $16 \%$ is needed for the laboratories without uncertainty to be comparable. The poor agreement obtained at $85^{\circ}$ indicates that the PV community should place minimal reliance on angular-dependent measurements made at this extreme angle until improvements can be demonstrated. The cloud-based Daidalos ray tracing model is used to simulate the angular-dependent losses of the mono-Si device and it is found that the simulation agrees to the median measurement within $0.6 \%$ for $\mathrm{AOI} \leq 70^{\circ}$ and within $1.4 \%$ for $\mathrm{AOI} \leq$ $80^{\circ}$. Finally, the impact that the angular-dependent measurement deviations have on climate specific energy rating (CSER) is evaluated for the six climates described in the IEC 61853-4 standard. When one outlier measurement is excluded, the angular-dependent measurements reported in this work cause a $1.0 \%-1.8 \%$ range in CSER and a 1.0\%-1.5\% range in annual energy yield, depending on the climate.

Table 1 Nomenclature

\begin{tabular}{|l|l|}
\hline$\Theta$ & Angle of incidence $\left(^{\circ}\right.$ ) \\
\hline$S T C$ & Standard Test Conditions of $1000 \mathrm{~W} \cdot \mathrm{m}^{-2}, 25^{\circ} \mathrm{C}$ and AM1.5G \\
\hline$E_{n}$ & ISO 17043 proficiency test performance statistic known as the ' $\mathrm{E}_{\mathrm{n}}$ number' (dimensionless) \\
\hline$\tau$ & $\begin{array}{l}\text { Measured relative light transmittance, also known as the incident angle modifier } \\
\text { (dimensionless) }\end{array}$ \\
\hline$\tau_{\text {spec }}$ & Simulated optical losses relative to the AM1.5G reference spectrum at normal incidence \\
\hline$a_{r}$ & Angular loss coefficient extracted from Martin and Ruiz model \\
\hline$b_{o}$ & Angular loss coefficient extracted from ASHRAE model \\
\hline$F_{D}$ & Correction factor for loss of diffuse irradiance due to reflection (dimensionless) \\
\hline$D_{\text {Corr,AOI }}$ & Plane of array diffuse irradiance corrected for reflection losses $\left(\mathrm{W} \cdot \mathrm{m}^{-2}\right)$ \\
\hline$B_{\text {Corr,AOI }}$ & Plane of array beam irradiance corrected for reflection losses $\left(\mathrm{W} \cdot \mathrm{m}^{-2}\right)$ \\
\hline $\mathrm{G}_{\text {Corr,AOI }}$ & Plane of array global irradiance corrected for reflection losses $\left(\mathrm{W} \cdot \mathrm{m}^{-2}\right)$ \\
\hline $\mathrm{Global} \mathrm{AAL}$ & Annual angular losses of global irradiance $(\%)$ \\
\hline
\end{tabular}

1 Introduction

Angular-dependent losses in photovoltaic (PV) devices are known to increase as function of a light source's angle of incidence (AOI) relative to the normal plane of the PV collector [1] - [3]. For PV modules with unsoiled planar glasses, these optical losses typically increase rapidly for $\mathrm{AOI}>50^{\circ}$. Such angulardependent losses are primarily due to reflection at the glass-air interface, but they also include absorption in the front materials and spectral effects [4]. The works of [5] and [6] have shown that annual angular losses for c-Si devices with cleaned planar glasses are between approximately 3-4\% when the PV module is mounted toward the equator with a tilt within $10^{\circ}$ of the latitude. Thus, AOI effects represent a major loss mechanism for PV devices. 
Angular-dependent losses are not characterized during measurements at Standard Test Conditions (STC), which are performed with the PV device at normal incidence to the light source $\left(\mathrm{AOI}=0^{\circ}\right)$. Unless dual axis tracking is used, the direct beam light that impinges on a PV module in the field will be at an $\mathrm{AOI} \neq 0^{\circ}$ for most of year. The IEC 61853 series of standards provide guidance on how to characterize PV devices over the breadth of environmental conditions known to influence PV performance, and among these are procedures for conducting AOI measurements [7].

Numerous interlaboratory comparisons have been conducted for PV measurements at STC [8] - [12], but the literature is comparatively sparse when it comes to comparisons of angular-dependent measurements. Our literature review revealed that the intercomparisons of $\mathrm{AOI}$ measurements to date have been conducted among few laboratories and have thus compared a limited number of test methods. For example, the authors in [13] compared outdoor measurements performed in real-time at Sandia National Laboratories (SNL) and CFV Labs, which lay roughly $10 \mathrm{~km}$ apart from each other. These two labs used unique methods to measure the AOI response of identical 36-cell $\left(0.65 \mathrm{~m}^{2}\right)$ PV modules and found an acceptable level of agreement between their measurements. The authors in [14] compared AOI measurements - also performed at SNL on full-size $\left(0.72-1.6 \mathrm{~m}^{2}\right)$ PV modules - to relative transmittance data supplied within the commercially available software PVsyst, or to measurements performed at an unnamed third party lab. The authors found that these three sources often had significant deviations for the same module type, and up to a $14 \%$ difference in relative transmittance at large AOIs. Finally, in a white paper published by PV Evolution Labs (PVEL), a comparison of five laboratories' angulardependent measurements on a commercially available PV module was presented, not of the angulardependent measurements themselves, but in the form of utility-scale PV energy simulations [15].

To the best of our knowledge, the scientific literature presently contains no published works of intercomparisons or "round-robin" measurement campaigns of angular-dependent measurements on PV devices beyond the aforementioned studies. Therefore, we conclude that an international intercomparison of angular-dependent measurements is needed to establish the present-day comparability of measurements made using various test methods that conform to the IEC 61853-2 standard. We presented a preliminary version of this effort in [16]. An overlapping objective in our previous paper and this work is to assess how well the measurement differences agree within the laboratories' stated expanded uncertainties. This contribution has two additional objectives: to compare the laboratory measurements to simulations performed using the Daidalos ray tracing model [17] [18], and to determine the impact the angular measurement discrepancies have on energy rating when different fitting models and diffuse models are used.

\section{Methods}

The participating laboratories measure short-circuit current $\left(I_{S c}\right)$ on all samples from $-85^{\circ}$ to $85^{\circ} \mathrm{AOI}$, except for two labs that only measured $I_{s c}$ in the positive angular direction. A common temperature coefficient for $I_{s c}$ was provided to the labs so measurements could be temperature corrected. Since the participants were asked to use their standard techniques for AOI measurements, they were afforded discretion concerning specific procedures such as measurement correction techniques and the number of readings to average at each $A O I$. For example, two labs determined that temperature corrections of $I_{s c}$ had a negligible influence on the overall uncertainty, and therefore chose not to temperature correct their $I_{s c}$ measurements. The same type of judgement was given to participants in applying corrections due to fluctuations in broadband irradiance. Most labs did apply irradiance stability corrections to $I_{s c}$ using readings from a reference device, but in some cases, the correction was not applied because the light source was determined to be stable throughout the test and/or a reference device was not used during the test. Only one laboratory reported implementing a spectral correction to $I_{s c}$ due to the change in 
spectrum during the test, which was performed outdoors. The labs were also permitted to decide how many $I_{s c}$ measurements at each $\mathrm{AOI}$ to average. This varied widely among labs with some labs performing as few as one and other labs performing more than one hundred $I_{s c}$ measurements per AOI. We refer the reader to Appendix 1, Table 5 for more information about the specific test methods employed by each lab.

In the results that follow the angular-dependent $I_{s c}$ measurements are converted to relative transmittance $\tau(\theta)$ (Eq. 1). The relative transmittance describes the photocurrent a PV device generates in the absence of diffuse light at a given $\mathrm{AOI}$ relative to the photocurrent the device would have generated if it exhibited a perfect cosine response (i.e. a Lambertian receiver). In this scheme, $\tau(\theta)$ is a dimensionless quantity wherein a value of 1 indicates the relative light transmission to the PV device follows that of a true cosine receiver and any values less than 1 indicate additional reflection and/or absorption. In other words, the quantity $1-\tau(\theta)$ is the amount of sunlight reflected and/or absorbed by the PV device's front materials, normalized to how much light is reflected or absorbed by the front materials at normal incidence. In practice the reflectance observed at normal incidence for the samples tested is of approximately $4 \%$. Note that the definition of $\tau(\theta)$ as it is presented here, is equivalent to the definition of the incident angle modifier (IAM) as described elsewhere in the literature [14], [19], [20].

$$
\tau(\theta)=\frac{I_{S C}(\theta)}{I_{S C}\left(0^{\circ}\right) \cdot \cos \theta}
$$

\subsection{Participating Laboratories and Measurement Systems}

Twelve laboratories from seven countries are involved in the measurement comparison. Descriptions of each laboratory, the measurement systems used, and selected methodological details are provided in Appendix 1, Table 5. The indoor measurement systems used at CIEMAT, CREST, Fraunhofer ISE, RETC, SUPSI and TNO are based on a flash system used for full-sized (roughly $1 \times 2 \mathrm{~m}$ ) modules. However, each one of these labs used a different approach to build the rotation stage. The rotation stage at TNO, for example is designed to measure small laminates (roughly $20 \times 20 \mathrm{~cm}$ ), while the CREST, Fraunhofer ISE, and SUPSI rotation stages can accommodate small laminates up to full-sized modules. The DTU system is only capable of testing small laminates and the PTB system can accommodate mini-modules with up to four 156 x 156 mm cells. The outdoor two-axis solar trackers at CENER, CFV Labs, and SNL can accommodate full-sized modules, and since small single cell laminates were used as the devices under test (DUTs) in this intercomparison, they utilized the trackers' area to perform the test on all DUTs at once.
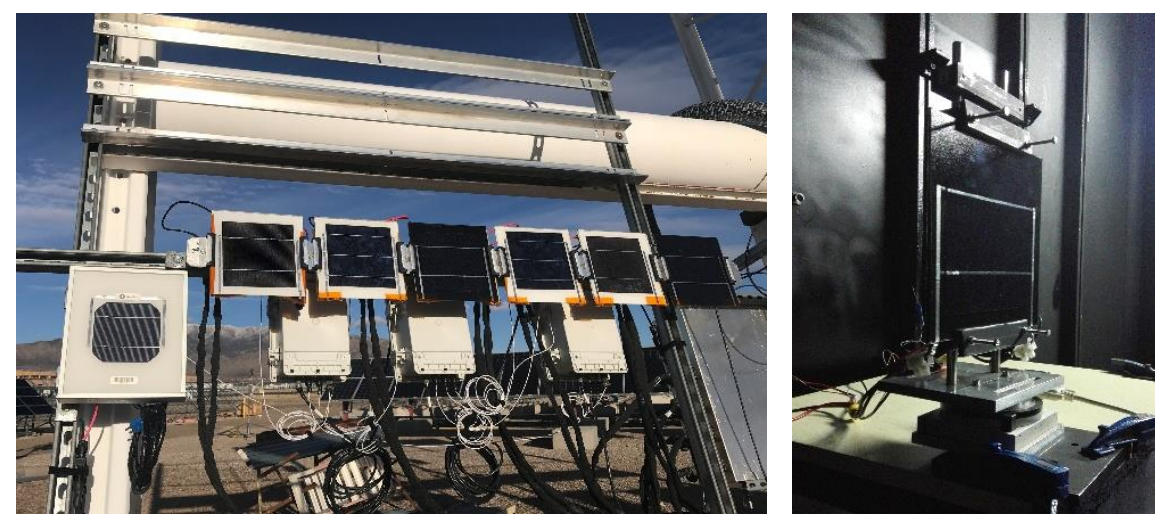

Figure 1: Photos from selected measurement systems. Intercomparison samples mounted on the dual axis tracker at Sandia National Laboratories (left) and a mono-Si sample mounted in the flash tunnel at CIEMAT (right). 
The expanded measurement uncertainty provided from eight of the twelve testing partners is shown in Figure 2. Three labs reported expanded uncertainties individually for each of the two DUTs. Figure 2 shows a trend of increasing uncertainty with increasing $\mathrm{AOI}$, wherein a range of $0.2 \%-1.1 \%$ at normal incidence and a range of $2.5 \%-30.7 \%$ at $85^{\circ} \mathrm{AOl}$ is observed. The specific reasons for this increasing trend will be unique to a given measurement system. Many authors have reported on the challenges and uncertainties encountered when directly measuring angular-dependent losses in PV devices [4], [21] - [26]. Some of these uncertainties exist in all AOI measurement systems, irrespective of the method. For example, common across measurement approaches is the fact that at AOls approaching $\rightarrow 80^{\circ}$, the $I_{s c}$ of the DUT can be an order of magnitude lower than at normal incidence. At such extreme angles, the $I_{s c}$ of the DUT and the equipment used to measure current can deviate from a linear response and this should be accounted for in the uncertainty budget. Additionally, when $\mathrm{AOI}>65^{\circ}$, the main contribution to overall uncertainty is likely to be the uncertainty from the measured angle $(\theta)$. Therefore, the wide range of reported measurement uncertainties at $85^{\circ}$ shown in Figure 2 is likely driven by the varying levels of accuracy in the measured angle $\theta$. For example, Lab J determined that the error of $\theta$ in their system at the time of measurement was approximately $2.3^{\circ}$, which was thus the major contributor to the total measurement uncertainty of nearly $30 \%$ at $85^{\circ}$. In contrast, Lab C, Lab D, Lab F and Lab K - all of which reported uncertainty less than $7.0 \%$ at $85^{\circ}$ - reported that the error of the measured angle $\theta$ was between $<0.1^{\circ}$ and $0.2^{\circ}$ in their respective measurement systems.

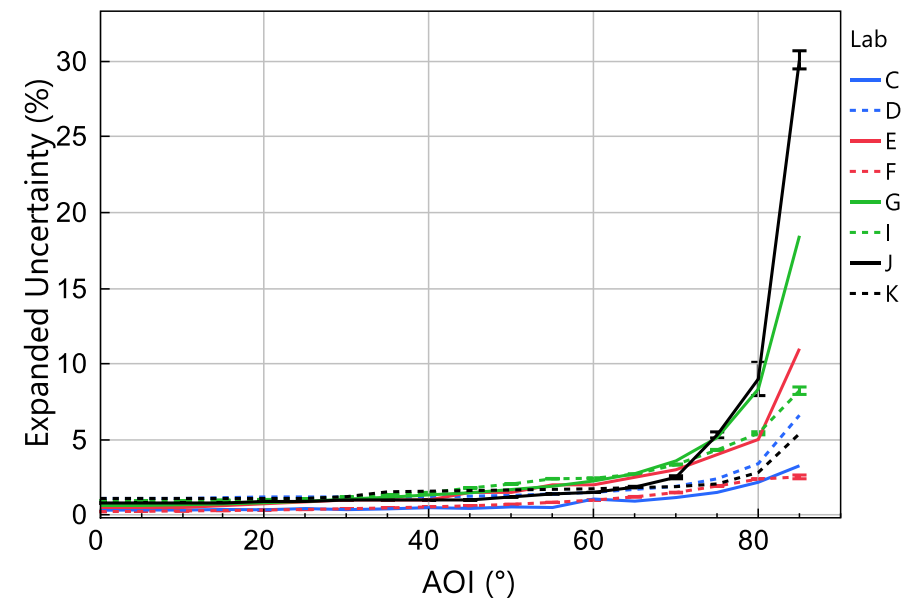

Figure 2: Expanded uncertainty of relative transmission measurements reported by eight laboratories as a function of AOI. The three labs with DUT-specific uncertainty are noted with range bars (Lab F, I, and J).
Some specific difficulties are encountered whether the angulardependent characteristics are measured indoors or outdoors. The major challenges for indoor measurements include suppression of diffuse light within the test bed (i.e. improving collimation), which can be accomplished using baffles such that the field of view to the module is restricted within $20^{\circ}$ to $30^{\circ}$ and implementing non-reflective surfaces that minimize reflections within the test bed.

Further challenges indoors include precisely positioning the DUT at the center of the rotational axis and maintaining low spatial irradiance non-uniformity as the device is rotated toward an increasing AOI. The IEC 61853-2:2016 standard specifies that the non-uniformity should remain lower than $5 \%$ throughout the test. However, [25] has demonstrated that when there is a $7.2 \mathrm{~m}$ distance from the light source to the DUT's optical axis, this non-uniformity requirement cannot be met when measuring commercially available PV panels that are $1 \mathrm{~m}$ in width. Another challenge is ensuring that the angular range of incident light on the DUT does not vary significantly throughout the duration of the test. The current (2016) edition of IEC 61853-2 specifies that the variation of AOI shall not vary by more than $1^{\circ}$, which is presently understood as the difference in AOls observed between the two active edges of the DUT that are closest and farthest away from the light source. However, [26] has shown that when commercially available solar simulators are used, this requirement can only be met for small-area samples, or when a subarea of a fullsize module is investigated either by mechanically isolating a single cell, or by partially shading the cell of interest. An intercomparison of AOI measurements on single cell laminates - as carried out in this work 
- should therefore allow participating laboratories to closely comply with the present requirements of the standard. Single cell laminates as DUTs also allows more laboratories and measurement systems to participate in the intercomparison. Specifically, five measurement systems used in this intercomparison are not capable of performing AOI measurements on full-size PV modules.

The primary challenges of performing angular-dependent PV measurements outdoors include correcting for environmental fluctuations during testing and quantifying the diffuse irradiance in the plane of the DUT. The plane of array diffuse irradiance $\left(D_{P O A}\right)$ contribution can be accounted for indirectly using cosine corrected direct beam measurements from a pyrheliometer and global measurements from a reference device. Alternatively $D_{P O A}$ can be measured directly if a specialized solar tracker is available as in [13]. Additionally, the pyranometers that are most often used as reference devices are not true cosine receptors [27]. Therefore, the sensitivity coefficients used should be uniquely calibrated for each value of $\theta$ under which the DUT is tested. Failure to apply such a correction could lead to errors of up to $12 \%$ [22], [24].

\subsection{Devices under Test (DUTs)}

Table 2 summarizes the bill of materials and the testing history of all DUTs distributed in this work. All 12 participating labs received a case of six samples that included three device types (mono-Si, BSi RIE, and BSi ADE). There was a duplicate sample of each type so there would be a backup in the case that any one sample became damaged during the measurement campaign. Before the intercomparison began, all DUTs were light soaked in the open-circuit state to a minimum dose of $10 \mathrm{kWh} \cdot \mathrm{m}^{-2}$ to remove initial light induced degradation (LID). A final stability check of $I_{s c}$ was not performed at the end of the intercomparison because the reported quantity $\tau(\theta)$ is calculated using a relative measurement approach. In other words, any minor degradation in the $I_{s c}$ during the measurement campaign would not impact the $\tau(\theta)$ results because these values are referenced to each individual laboratory's $I_{s c}$ measurement at normal incidence. Therefore, the electroluminescence (EL) imaging performed by each laboratory before the AOI tests was considered adequate to detect any changes in cell-level performance that could potentially impact the test results.

The following specifications are common to all DUTs: (i) An active cell area of $156 \mathrm{~mm} \times 156 \mathrm{~mm}$; (ii) full area dimensions of $200 \mathrm{~mm} \times 200 \mathrm{~mm}$; (iii) $3.2 \mathrm{~mm}$ thickness, low-iron, non-coated, finely textured PV glass superstrate; (iv) ethylene-vinyl acetate (EVA) encapsulant; (v) two tabs as metal contacts; and (vi) a flat polymeric backsheet with slight curvature around the cell edges. The differences between the samples are the cell type, the cell texturing, and the backsheet color. One sample type has a mono-crystalline Czochralski grown silicon (mono-Si) cell textured by a conventional random pyramid etch using $\mathrm{KOH}$ and will be referred to as 'mono-Si' hereafter. The second sample type has a multi-crystalline black silicon (BSi) cell textured under a mask-less reactive ion etching (RIE) process that results in $\sim 400 \mathrm{~nm}$ tall conical-like hillocks as described in [28]; this device type will be referred to as 'BSi RIE' hereafter. The third sample type has a multi-crystalline cell textured by atmospheric dry etching (ADE) resulting in $\sim 450 \mathrm{~nm}$ rounded cones after a wet-chemical post-etching [29] and is referred to as 'BSi ADE' hereafter. The edges of the DUTs were covered with non-transparent tape to prevent measurement artifacts at large incident angles. All the DUTs have a greater ratio of visible backsheet to active cell area than is typical of commercially available PV modules; this is due to the availability of $20 \mathrm{~cm} \times 20 \mathrm{~cm}$ glass sheets and conventional 156 $\mathrm{mm} \times 156 \mathrm{~mm}$ PV cells. 
Table 2: Descriptions of the DUTs distributed to all participants in the intercomparison. When cells in the 'Testing Outcome and Data Usage' column are highlighted green, this indicates that the angular-dependent measurements of the DUT are reported in this manuscript.

\begin{tabular}{|c|c|c|c|c|c|}
\hline $\begin{array}{l}\text { Serial } \\
\text { Number } \\
\text { (SN) }\end{array}$ & Testing Outcome and Data Usage & $\begin{array}{l}\text { Device } \\
\text { Type } \\
\text { (Alias) }\end{array}$ & $\begin{array}{l}\text { Cell Type }^{1} \\
\text { and Surface } \\
\text { Texture }\end{array}$ & $\begin{array}{c}\text { Glass } \\
\text { Specifications }^{2}\end{array}$ & $\begin{array}{l}\text { Encapsulant } \\
\text { and } \\
\text { Backsheet }\end{array}$ \\
\hline 0008 & $\begin{array}{l}\text { Sent to all } 12 \text { labs. Results from } 10 \\
\text { of } 12 \text { labs presented here. Lab D } \\
\text { and Lab L measurements not } \\
\text { presented because they were } \\
\text { determined as outliers in [16]. }\end{array}$ & \multirow{4}{*}{$\begin{array}{l}\text { mono- } \\
\mathrm{Si}\end{array}$} & \multirow{4}{*}{$\begin{array}{l}\text { mono-Si cell } \\
\text { with } \\
\text { Random } \\
\text { pyramids } \\
\text { from KOH }\end{array}$} & \multirow{4}{*}{$\begin{array}{c}\text { Manufacturer } \\
\text { A }\end{array}$} & \multirow{4}{*}{$\begin{array}{c}\text { EVA } \\
\text { encapsulant } \\
\text { / Polymeric } \\
\text { black } \\
\text { backsheet }\end{array}$} \\
\hline 0010 & $\begin{array}{l}\text { Sent to Lab D for retest. Results are } \\
\text { presented here together with } \\
\text { 'mono-Si' test results (SN 0008). }\end{array}$ & & & & \\
\hline 0015 & $\begin{array}{l}\text { Sent to Lab L for retest. Results are } \\
\text { presented here together with } \\
\text { 'mono-Si' test results (SN 0008). }\end{array}$ & & & & \\
\hline 0020 & $\begin{array}{l}\text { Sent to } 12 \text { labs. Damaged glass edge } \\
\text { found during visual inspection. } \tau(\theta) \\
\text { results not presented. }\end{array}$ & & & & \\
\hline 0025 & $\begin{array}{l}\text { Sent to all } 12 \text { labs. Results from } 10 \\
\text { of } 12 \text { labs presented here. Lab D } \\
\text { and Lab L measurements not } \\
\text { presented because they were } \\
\text { determined as outliers in [16]. }\end{array}$ & \multirow[t]{2}{*}{$\begin{array}{l}\text { BSi } \\
\text { RIE }\end{array}$} & \multirow[t]{2}{*}{$\begin{array}{l}\text { multi-Si cell } \\
\text { with } \\
\text { conical-like } \\
\text { hillocks } \\
\text { from RIE }\end{array}$} & \multirow{4}{*}{$\begin{array}{l}\text { Manufacturer } \\
\text { B }\end{array}$} & \multirow{4}{*}{$\begin{array}{c}\text { EVA } \\
\text { encapsulant } \\
\text { / Polymeric } \\
\text { white } \\
\text { backsheet }\end{array}$} \\
\hline 0026 & $\begin{array}{l}\text { Sent to } 12 \text { labs. Duplicate DUT of SN } \\
\text { 0025. } \tau(\theta) \text { results not presented. }\end{array}$ & & & & \\
\hline 0027 & $\begin{array}{c}\text { Sent to all } 12 \text { labs, but } \\
\text { measurements not presented due } \\
\text { to lack of dataset completeness and } \\
\text { lack of distinctiveness in angular- } \\
\text { dependent response compared to } \\
\text { mono-Si or BSi RIE devices. }\end{array}$ & \multirow[t]{2}{*}{$\begin{array}{c}\text { BSi } \\
\text { ADE }\end{array}$} & \multirow[t]{2}{*}{$\begin{array}{l}\text { multi-Si cell } \\
\text { with } \\
\text { rounded } \\
\text { cones from } \\
\text { ADE }\end{array}$} & & \\
\hline 0028 & $\begin{array}{l}\text { Sent to all } 12 \text { labs. Significant cell } \\
\text { cracks found in EL image. } \tau(\theta) \text { results } \\
\text { not presented here. }\end{array}$ & & & & \\
\hline
\end{tabular}

${ }^{1}$ All cells are a $156 \mathrm{~mm} \times 156 \mathrm{~mm}$ square (multi-Si) or pseudo square (mono-Si).

${ }^{2}$ The glass specifications are the same for all samples (i.e. $200 \mathrm{~mm} \times 200 \mathrm{~mm}, 3.2 \mathrm{~mm}$ thickness, low-iron, noncoated, finely textured), but they were procured from two different manufacturers noted here as 'Manufacturer $A$ ' and 'Manufacturer B'. 
The convention regarding the axis of rotation was predefined to allow the results from the different partners to be directly comparable. The definition for which angular direction was positive and negative was made explicitly clear in a memorandum document that all partners received. The document also specified the location of the rotational axis and tolerances for the precise location of the front of the PV cell surface within the laminate. The samples made for this round-robin have an offset of approximately
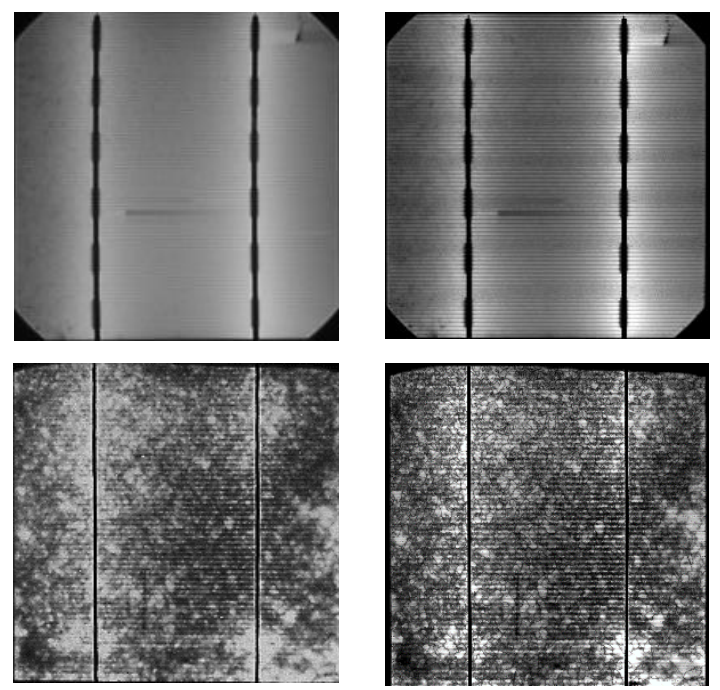

Figure 3: EL images taken before the intercomparison started (left) and EL images of the same devices taken two years later upon completion of the measurement campaign (right). Top images are the mono-Si sample with standard texturing (SN 0008) and bottom images are the BSi RIE nanostructured sample (SN 0026). Two BSi RIE samples were sent to all 12 labs for characterization, and the EL shown here is the highest quality of the two.

$1.5 \mathrm{~mm} \pm 0.5 \mathrm{~mm}$ from the rear side (backsheet) to the front surface of the PV cell.

EL images were taken before each laboratory started testing to ensure that no damage occurred due to transportation or handling. The glass of one mono-Si sample (SN 0020) was damaged about halfway through the campaign, and one BSi ADE sample (SN 0028) experienced extreme cell cracking near the end of the campaign. These damaged test samples highlight the necessity of duplicate samples in roundrobin style measurement campaigns. The labs were asked to measure all six samples that they received, but unfortunately two labs only measured three samples (i.e. they only measured SN 0008, SN 0025, SN 0028, and not the duplicate samples). Of these three, BSi ADE sample SN 0028 was later found to have significant cell damage, which compromised the completeness of the measurement results from that sample type. Furthermore, the reported angulardependent measurements of the three device types with different cell textures were consistent with previous authors [22] [30] in that they did not significantly differ from each other when encapsulated with similar or identical glass superstrates. Therefore, the results from the BSi ADE sample type are not presented here. Regarding the two sample types that are presented in this work (mono-Si and BSi RIE), the EL images taken before the first lab's measurement and after the final lab's measurement showed that no damage had occurred during the measurement campaign (Figure 3).

In our previous work [16], we determined that Lab D's and Lab L's initial AOI measurements on all samples contained outlier measurements at AOls between $45^{\circ}$ and $85^{\circ}$. Therefore, two additional mono-Si samples were sent to these labs for retests: One sample (SN 0010) was sent to Lab D, and the other sample (SN 0015) was sent to Lab L. Sending new samples allowed the intercomparison to continue as planned while Lab D and Lab L completed their retests in parallel. In the sections that follow, the results from Lab D and Lab L's retests are shown together with measurements on a separate - but equivalent - mono-Si sample (SN 0008). The homogeneity of mono-Si samples SN 0010, SN 0015, SN 0008 was first established given that they were produced in the same batch using identical bills of materials from the same manufacturers. The equivalence of their angular-dependent responses was established with measurements performed at DTU, prior to shipment to Lab D and Lab L. The DTU measurements showed $\tau(\theta)$ deviations less than 0.003 $(0.3 \%)$ for most AOls and a maximum deviation of $0.0046(0.46 \%)$ that occurred at $85^{\circ} \mathrm{AOI}$. Therefore, the results from Lab D and Lab L's retest measurements on SN 0010 and SN 0015 are included with the results from SN 0008; the results from all three samples are reported as the mono-Si device type. 


\subsection{Analysis}

This section describes the main methods used to analyze the angular-dependent measurements.

\subsubsection{Statistical Analysis using the $E_{n}$ Number Approach}

The expanded uncertainty of each lab's measurements is critical for establishing comparability through the $E_{n}$ number calculation (Eq. 2) per ISO 17043 [31]. Therefore, the labs that were not able to provide measurement uncertainty are removed from the $E_{n}$ number proficiency assessment, and a separate analysis is performed. In this separate analysis, we show the lowest measurement uncertainty that is needed to be comparable to the labs that did provide uncertainty. We use the well-known Tukey outlier box plot to identify outliers in the laboratories' $\tau(\theta)$ measurements prior to calculation of the consensus (i.e. reference) values. This exercise revealed several outliers in the $\tau(\theta)$ values reported by Lab J at AOIs between $10^{\circ}$ and $85^{\circ}$. Therefore, Lab J's results were excluded in the derivations of consensus values shown in Eq. 3 and Eq. 4. When measurement uncertainty is available, an $E_{n}$ number is calculated for each sample at each $\mathrm{AOI}$ as:

$$
E_{n}=\frac{x_{i}-X_{r e f, i}}{\sqrt{U c_{i}^{2}+U c_{r e f, i}^{2}}}
$$

Wherein $x_{i}$ is the individual laboratory's measured relative transmittance $\tau(\theta)$ and $U C_{i}$ is the expanded uncertainty of the lab's measurement of $\tau(\theta)$ with a confidence level of approximately $95 \%$. The reference value $X_{\text {ref, } i}$ is the weighted mean of seven partner's measured $\tau(\theta)$ values for a given sample at a given angle. Here the measurements are weighted by the uncertainty provided by each partner. Weighting the results in this manner has the consequence of shifting the $X_{\text {ref }}$ value towards the measured values $\left(x_{i}\right)$ of the laboratories with lower uncertainty. For every sample and every angle, the $X_{\text {ref,i }}$ value is calculated as:

$$
X_{\text {ref }, i}=\frac{\sum_{i=1}^{N} \frac{x_{i}}{\sigma_{i}^{2}}}{\sum_{i=1}^{N} \frac{1}{\sigma_{i}{ }^{2}}}
$$

wherein $\sigma_{i}$ is the standard uncertainty $(\mathrm{k}=1)$ of the lab's measurement. We assume that the values of $\sigma_{i}$ are mutually uncorrelated, and therefore an inverse-variance weighting procedure is used. Finally, $U C_{r e f, i}$ is the expanded combined uncertainty of $X_{\text {ref }, i}$ and is calculated as:

$$
U C_{r e f, i}=\frac{2}{\sqrt{\sum_{i=1}^{N} \frac{1}{\sigma_{i}^{2}}}}
$$

Calculating $U C_{\text {ref }}$ in this way yields a value that is always lower than any of the participating labs' declared uncertainties. For example, the lowest reported measurement uncertainty at $0^{\circ} \mathrm{AOI}$ is $0.2 \%$ while $U C_{\text {ref }}$ is $0.1 \%$; And at $85^{\circ} \mathrm{AOI}$, the lowest reported uncertainty is $2.5 \%$ while $U C_{\text {ref }}$ is $1.8 \%$. The relative transmittance measurements from each laboratory are said to be in agreement with each other when -1 $\leq E_{n} \leq 1$. In other words, the condition $-1 \leq E_{n} \leq 1$ is met when the difference between a lab's measurement $\left(X_{i}\right)$ and the reference value $\left(X_{r e f, i}\right)$ is less than or equal to the square root of square sum of the lab's declared uncertainty $\left(U C_{i}\right)$ and the reference uncertainty $\left(U C_{r e f, i}\right)$. The sign of $E_{n}$ provides a convenient way of discerning whether a lab's measurement is high $\left(E_{n}>0\right)$ or low $\left(E_{n}<0\right)$ relative to the weighted group mean.

\subsubsection{Comparison of Measurements to Simulations}

Given the many challenges with directly measuring the angular-dependent response of PV devices it can be of value to have a simulation model for comparisons and additional analysis. Because it is difficult to model the sub-wavelength BSi texture [32] and much larger DUT features like glass and metal contacts all 
in one model, we only use the mono-Si sample for comparison where all features can be modeled accurately. We show how the relative transmittance measurements made on the standard mono-Si sample compare to simulated values using the cloud-based version of the Daidalos ray tracing framework, which is developed by ISFH [33] [34] and accessible to the PV scientific community at no cost [35]. Daidalos models the glass cover, the encapsulation, the cell metallization and the cell texture as 3D geometries with spectrally resolved complex refractive index values. As output, Daidalos gives spectrally resolved absorptance and reflection curves for each component of the PV device. These curves are then multiplied with the AM1.5G spectrum in units of photo current and integrated over the wavelength range from $300 \mathrm{~nm}$ to $1200 \mathrm{~nm}$ to obtain the PV device short-circuit current. As inputs, the measured spectral reflectance of the backsheet before encapsulation, and the measured height and pitch of the silver grid fingers from an optical profilometer are used together with spectrally resolved complex refractive index values for the other components taken from literature [36]. To verify the spectral behavior of the Daidalos model, we use measured external quantum efficiency (eQE) data from PTB's differential spectral responsivity system under $350 \mathrm{~W} \cdot \mathrm{m}^{-2}$ white light bias irradiation without consideration for device nonlinearity.

An advantage of these ray tracing simulations over measurements is that the amount of lost incoming light due to reflection or absorption at specific parts of the PV module can be determined. To investigate the angular behavior of these losses, we use a modified version of the relative transmittance $\tau_{\text {spec, }}$, where the angle dependent loss current equivalents $I_{x}$ are used in the numerator and the incoming photo current $I_{\text {spec }}\left(0^{\circ}\right)$ is used in the denominator.

$$
\tau_{\text {spec }}(\theta)=\frac{I_{x}(\theta)}{I_{\text {spec }}\left(0^{\circ}\right) \cdot \cos \theta}
$$

\subsubsection{Fitting Models to Angular-dependent Measurements}

Several authors have described mathematical models for fitting measured angle-dependent transmittance curves of PV devices [19] and [37] - [39]. The IEC 61853-2 and IEC 61853-3 standards adopt the Martin and Ruiz model, which uses a single parameter $a_{r}$ to describe angular reflection losses [40]. This model is shown in Eq. (6) below.

$$
\tau(\theta)=\frac{1-\exp \left(-\cos \theta / a_{r}\right)}{1-\exp \left(-1 / a_{r}\right)}
$$

In addition to the PV-specific fitting models, a model developed by [39] for solar thermal collectors was developed in the 1960's. This model was adopted by ASHRAE and is still used by PV modelers today [41], [42]. Similar to the Martin and Ruiz model, the ASHRAE model uses single parameter $b_{0}$ to describe angular reflection losses as shown below.

$$
\tau(\theta)=1-b_{0}\left(\frac{1}{\cos \theta}-1\right)
$$

The current (2016) edition of IEC 61853-2 provides no specific guidance on how to extract the $a_{r}$ coefficient from the analytical function (Eq. 6). Since different fitting procedures could lead to disparate coefficients, the participating laboratories did not report angular loss coefficients. Instead, we extracted the angular loss coefficients $a_{r}$ and $b_{o}$ at the end of the measurement campaign using a common method for all participant's measurement data. The method uses a Gauss-Newton least squares fitting approach that minimizes the sum of squared errors (SSE) and weights measurements at all AOIs equally. No significant impact was observed on the coefficients or energy rating when using a fitting procedure that weighted the measurements according to the reported uncertainty at each AOI. We obtained coefficients from measurements made in the negative and positive angular directions and the coefficients reported here are the average of the two directions. Once the angular loss coefficients are obtained, the aforementioned 
formulae can subsequently be used in energy rating and/or energy yield calculations as will be shown below.

\subsubsection{Impact of Laboratory Measurement Differences on Energy Rating}

The ultimate outcome of the four part series of IEC 61853 Energy Rating standards is the determination of the PV module's climate specific energy rating (CSER) [43]. The CSER is essentially a DC level performance ratio (PR) of a single module that describes the annual deviation in energy production in a given climate, relative to what the module could have produced if it were operating at its STC performance. Unlike the classic definition of PR, the CSER does not incorporate losses due to soiling, shading, degradation, or any inverter specific losses such as efficiency of power conversion, maximum power point tracking efficiency or clipping losses. According to [44] the CSER and annual energy yield are simply intended for PV module buyers and system developers to assess the relative performance of PV technologies across climates. The CSER is calculated per the formula below where $E[W h]$ is the annual energy produced by the PV device, $G_{0}$ is the reference irradiance of $1000 \mathrm{~W} \cdot \mathrm{m}^{-2}, P_{S T C}$ is the PV device maximum power at standard conditions, and $H\left[W h \cdot \mathrm{m}^{-2}\right]$ is the annual in plane insolation before correction for angular losses and spectral effects.

$$
\text { CSER }=\frac{E \cdot G_{O}}{P_{S T C} \cdot H}
$$

TÜV Rheinland has provided multi-irradiance and temperature performance data (i.e. the IEC 61853-1 matrix) and spectral responsivity measurements for a conventional crystalline silicon 60-cell PV panel. We use theoretical values for thermal heat transfer coefficients $U_{0}=25 \mathrm{~W} \cdot \mathrm{m}^{-2} \cdot \mathrm{K}$ and $U_{1}=6.84 \mathrm{~W} \cdot \mathrm{m}^{-3} \cdot \mathrm{K} \cdot \mathrm{s}$, which are taken from [45]. With these data, and the relative light transmission data from the participating labs, we calculate CSER for the six climate regions described in the IEC 61853-4 standard. The accuracy of our program that implements the IEC 61853-3 energy rating algorithm has been established in a parallel intercomparison [46].

\subsection{Annual Angular Losses Calculated with Different Diffuse Models}

As mentioned previously, the IEC 61853 Energy Rating standards use the Martin and Ruiz fitting model. We investigate the impact that the choice of fitting model has on the annual angular performance losses by repeating the calculations using the ASHRAE fitting model. Furthermore, we investigate how two different methods to apply the angular losses to the diffuse radiation component affect the results. These two methods include numerical integration and closed-form analytical approximations. The purpose of these tests is to explore the range of annual angular losses (AAL) that can be obtained due to differences in angular-dependent measurements from the participating labs and due to different approaches used to apply angular-dependent losses to diffuse radiation. The authors in [6] showed that the AAL of diffuse radiation can change by up to $0.5 \%$ based on the model used to transpose horizontal diffuse radiation to a tilted surface. Because this impact is relatively small, we forego investigations into the effect that the choice of transposition model has on AAL calculations by using the in-plane irradiance provided in the standard data sets. A summary of the different methods used to calculate AAL are shown in Table 3.

The IEC 61853-3 standard specifies that the angular-dependent losses associated with the diffuse component shall be calculated using the closed-form analytical approximation as proposed in [2] and shown below. The AOI corrected diffuse irradiance in the plane of array $D_{\text {corr,AOI }}$ is calculated using the diffuse angular loss factor $\left(F_{D}\right)$.

$$
\begin{gathered}
F_{D}=\left(1-\exp \left[-\frac{1}{a_{r}}\left(\frac{4}{3 \pi} \cdot \Delta+\left(0.5 \cdot a_{r}-0.154\right) \cdot \Delta^{2}\right)\right]\right) \\
\Delta=\sin \beta+\frac{\pi-\beta-\sin \beta}{1+\cos \beta}
\end{gathered}
$$


Where $\beta$ is the PV collector's tilt angle from a horizontal. In all our calculations, we use $\beta=20^{\circ}$, according to the standard. Once $F_{D}$ is calculated, the diffuse irradiance in the plane of array $\left(D_{P O A}\right)$ is corrected for reflection losses using Eq. (11).

$$
D_{\text {corr }, A O I}=D_{P O A} \cdot F_{D}
$$

Eq. (9) can only be used with the $a_{r}$ coefficient extracted from Eq. (6). Therefore, we calculate $D_{\text {corr,Aol }}$ using the $b_{0}$ coefficient from the ASHRAE model using a closed-form approximation as proposed by [20] and shown in Eq. (12) where DHI is the diffuse irradiance on a horizontal plane.

$$
D_{\text {corr }, A O I}=D_{P O A} \cdot\left(1-b_{0}+2 \frac{b_{0} \beta}{\pi}\right)
$$

Finally, we calculate $D_{c o r r, A O I}$ using the spherical integration method as described in [47]. This method permits the calculation of the AOI corrected diffuse radiation using any fitting model, either the Martin and Ruiz model, ASHRAE model, or otherwise. In the spherical integration method, the model specific relative transmittance $\tau(\theta)$ function is applied at each solid angle viewed by the PV module and weighted by cosine of $\theta$. Indeed the work of [47] contains a methodology to account for the circumsolar and horizon brightening components of diffuse irradiance, and [48] provides a model that describes the spectral and directional and properties of diffuse irradiance, but we simplify our calculations by assuming an isotropic sky.

Table 3: List of fitting model and diffuse models used in the calculation of global annual angular losses. All methods assume an isotropic sky diffuse component.

\begin{tabular}{|l|l|l|l|}
\hline Method & Data Fitting Model & $\begin{array}{l}\text { Method to Apply Angular- } \\
\text { dependent Losses to DPOA }\end{array}$ & Ref. \\
\hline 1 & Martin \& Ruiz (Eq. 6) & Closed form approximation (Eq. 9) & {$[2]$} \\
\hline 2 & Martin \& Ruiz (Eq. 6) & Numerical integration & {$[47]$} \\
\hline 3 & ASHRAE (Eq. 7) & Closed form approximation (Eq. 12) & {$[20]$} \\
\hline 4 & ASHRAE (Eq. 7) & Numerical integration & {$[47]$} \\
\hline
\end{tabular}

In all AAL calculations, we calculate the plane of array beam irradiance corrected for reflection losses via

$$
B_{\text {corr }, A O I}=B_{P O A} \cdot \tau(\theta)
$$

Wherein $B_{P O A}$ is the beam irradiance in the POA and $\tau(\theta)$ is the relative transmittance of the PV device using the Martin an Ruiz model (Eq. 6) or ASHRAE model (Eq. 7). AOI corrected global irradiance $G_{\text {corr,AOI }}$ is then calculated by summation of the AOI corrected diffuse and beam components.

$$
G_{\text {corr }, A O I}=D_{\text {corr }, A O I}+B_{\text {corr }, A O I}
$$

Angular losses from ground reflections are not considered in the IEC 61853 Energy Rating normative nor are they considered here. This is because the calculations consider a mono-facial PV module with a static tilt angle of $20^{\circ}$. In this scenario, the module's view factor of the ground is on the order of $3 \%$, and when this view factor is multiplied by the albedo, the contribution of irradiance from ground reflections is considered negligible. Finally, the AAL of global irradiance in each climate is calculated by the difference of annual hourly $G_{C O R R, A O I}$ and $G_{P O A}$ as shown below in Eq. 15. $G_{P O A}$ refers to the global in irradiance before reflection losses and $G_{C O R R, A O I}$ is the effective irradiance available to the PV cells after angular losses have been applied. 


$$
\text { Global } A A L=\frac{\sum G_{c o r r, A O I}-\sum G_{P O A}}{\sum G_{P O A}}
$$

\subsection{Comparability of Angular-dependent Measurements among Laboratories}

The top frame of Figure 4 shows the median $\tau(\theta)$ measurements of the mono-Si and BSi RIE sample types. The BSi RIE sample type shows less reflection loss than the mono-Si sample, but the difference between the two sample types is always $<0.015$. The modest improvement in angular-dependent performance could be due to a combination of the BSi nanostructure and the white backsheet. The bottom frame of Figure 4 shows box plot distributions of the differences between each lab's $\tau(\theta)$ measurement and the weighted mean $X_{\text {ref. }}$. The $y$-axis of the bottom graph in Figure 4 shows the numerator of the $E_{n}$ calculation in Eq. 2, where $X_{\text {ref }}$ is calculated based on measurements from only seven of the eight labs that reported uncertainty. The overall agreement is within $\pm 2 \%$ until about $\mathrm{AOI}=65^{\circ}$, but from $70^{\circ}$ to $85^{\circ}$ the range excluding outliers - increases rapidly from $2.5 \%$ to $23 \%$. There are four outliers not shown in Figure 4 that occur at $\pm 85^{\circ}$. These outliers are between $44 \%$ and $24 \%$ low to the weighted mean $X_{\text {ref. }}$. All four extreme outliers at $\pm 85^{\circ}$ were reported by Lab J. As described in Section 2.2, Lab D and Lab L performed retests on two separate mono-Si samples, which were not measured by the other labs, but determined as equivalent test devices. The initial measurements from Lab $D$ and Lab $L$ can be found in our previous work [16]; the improvements shown here are believed to be from a reduction of stray light within the testbed and better alignment of the DUT in the optical axis of rotation.

At large AOls in both the positive and negative direction, we observed that the range of $\tau(\theta)$ measurements is higher for the BSi RIE sample than for the mono-Si sample. This could be due to the nature of the BSi nanostructures, which create a graded refractive index at the Si-EVA interface. The graded refractive index principle differs fundamentally to the anti-reflection mechanism of the random pyramid structure on the mono-Si sample, where photons are reflected off the pyramid sidewalls and on average are absorbed in adjacent pyramids. Furthermore, the variance of the BSi nanostructure topology may not be similar to that of the conventional random pyramids over large areas. This means at large AOls the nanostructured surface may still reflect as a graded refractive index, but deviations in collimation and topology across the cell may instead result in the response of a planar Si surface. At small AOls the BSi has a graded refractive index, which more effectively suppresses broadband light. These factors can make reproducible measurements on BSi challenging, particularly at large AOls. 


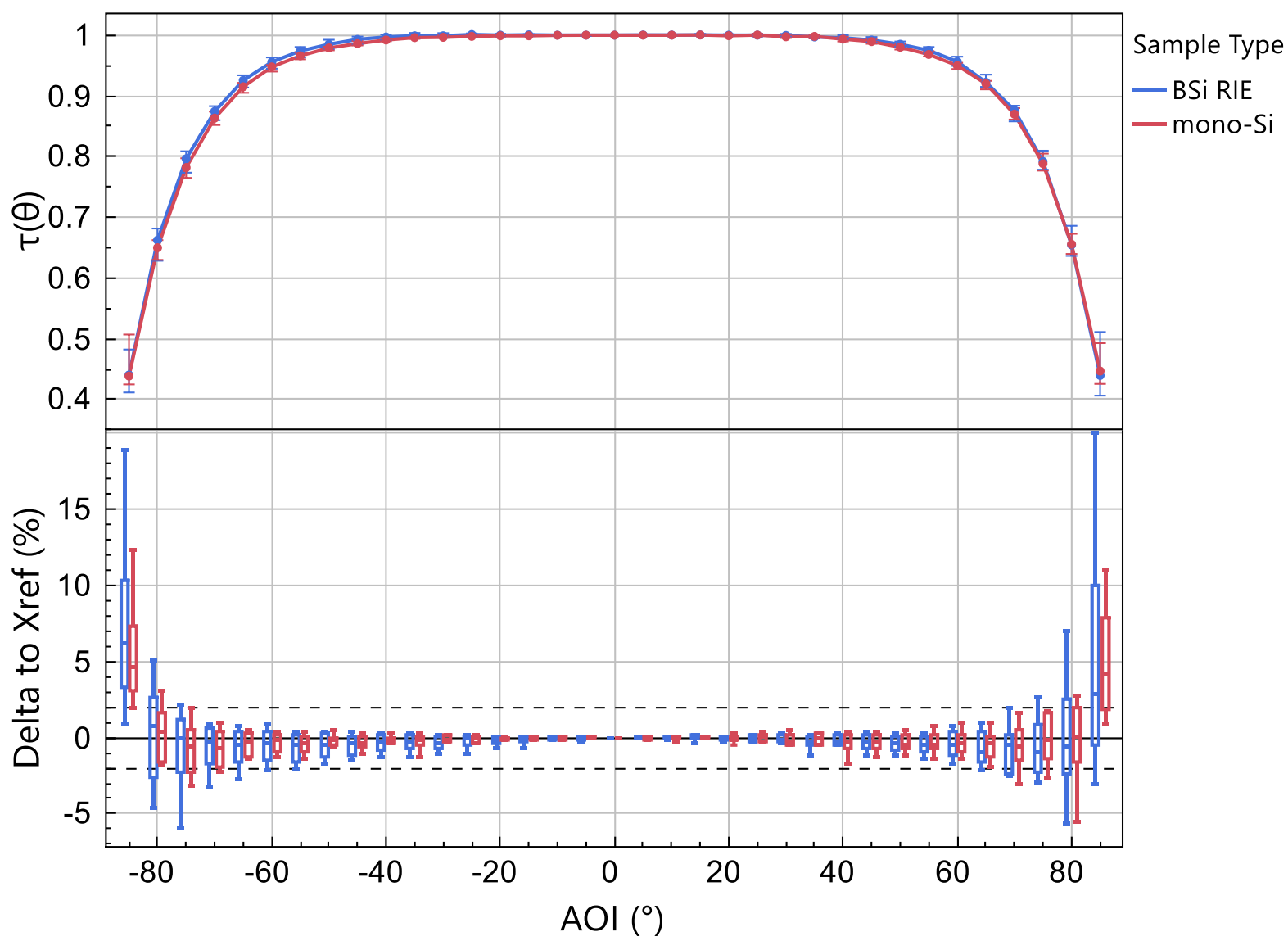

Figure 4: Results from all laboratories. Top - Median measured relative transmission at each AOI for two sample types. The error bars at each AOI show the interquartile range. Bottom - Box plots showing the differences to the weighted mean $X_{\text {ref. }}$ The dashed reference lines are drawn at $\pm 2 \%$. Note that at $\pm 85^{\circ}$ there are 4 outliers ranging from $-44 \%$ to $-24 \%$, which are not shown. $X_{\text {ref }}$ is calculated based on the measurements from seven labs that reported expanded uncertainty.

Results for the $E_{n}$ number proficiency assessment (Eq. 2) are shown in Figure 5. Recall that Lab J has been removed from this analysis and their results are instead assessed in Figure 6 . The dashed red lines in Figure 5 indicate the \pm 1 conformity boundaries according to ISO 17043. There are only five instances outside this boundary - four of which belong to Lab C and one to Lab E - and all of which occur at AOIs $\geq 50^{\circ}$. The greatest dispersion in $E_{n}$ values is observed at $85^{\circ}$, which indicates that reproducible angulardependent measurements at $85^{\circ}$ are currently the most challenging to obtain among leading PV laboratories.

The root causes for the measurement discrepancies are difficult to identify because the exact reasons could include any combination of the general challenges and uncertainties that were mentioned in Section 2.1. However, given that the largest discrepancies among labs occur at large AOls, and that the largest single uncertainty component at such steep angles is typically the uncertainty of the measured angle $\theta$, a major reason is likely due to mounting errors or inaccurate measurement of $\theta$. The current (2016) edition of IEC 61853-2 specifies that the accuracy of the AOI between DUT and light source must be $\pm 1^{\circ}$ or better for indoor measurements, and $\pm 0.5^{\circ}$ or better for outdoor measurements. To the best of our knowledge all the participating labs employed rotation stages that meet or go beyond this requirement. This suggests that a more stringent requirement for determination of $\mathrm{AOI} \theta$ could be necessary to achieve better reproducibility in angular-dependent measurements at $85^{\circ}$. 
Future interlaboratory comparisons of angular-dependent measurements could employ procedures that aim to minimize mounting error. For example, such error could potentially be mitigated by using DUTs with a standardized clamping system, or by using DUTs with frames that are already compatible in all participating labs' measurement systems. During our measurement campaign, some labs reported that they needed to devise custom solutions to mount the $20 \times 20 \mathrm{~cm}$ frameless DUTs in their measurement systems. Such need for ad hoc solutions should be avoided in future interlaboratory comparisons of angular-dependent measurements to allow the labs to adhere to their standard measurement practices as closely as possible.

Additional actions could be taken to remediate the unsatisfactory agreement at large AOls. The first is that the labs not meeting the condition $\left|E_{n}\right| \leq 1$ should adopt a more conservative measurement uncertainty. This is particularly true in the case of lab $C$ that reported one of the lowest measurement uncertainties out of the eight labs in Figure 2. The second action is that researchers and PV industry professionals in general should place minimal confidence on angular-dependent measurements made at $85^{\circ}$ until improved measurement agreement and reduced uncertainty can be demonstrated. A final possibility is that future revisions of the IEC 61853-2 standard could specify that measurements at $85^{\circ} \mathrm{AOI}$ are optional. In Section 3.2 we will explore how modeled angular-dependent performance can be used as a substitute to measurements, which can be useful when accuracy is compromised by high measurement uncertainty.
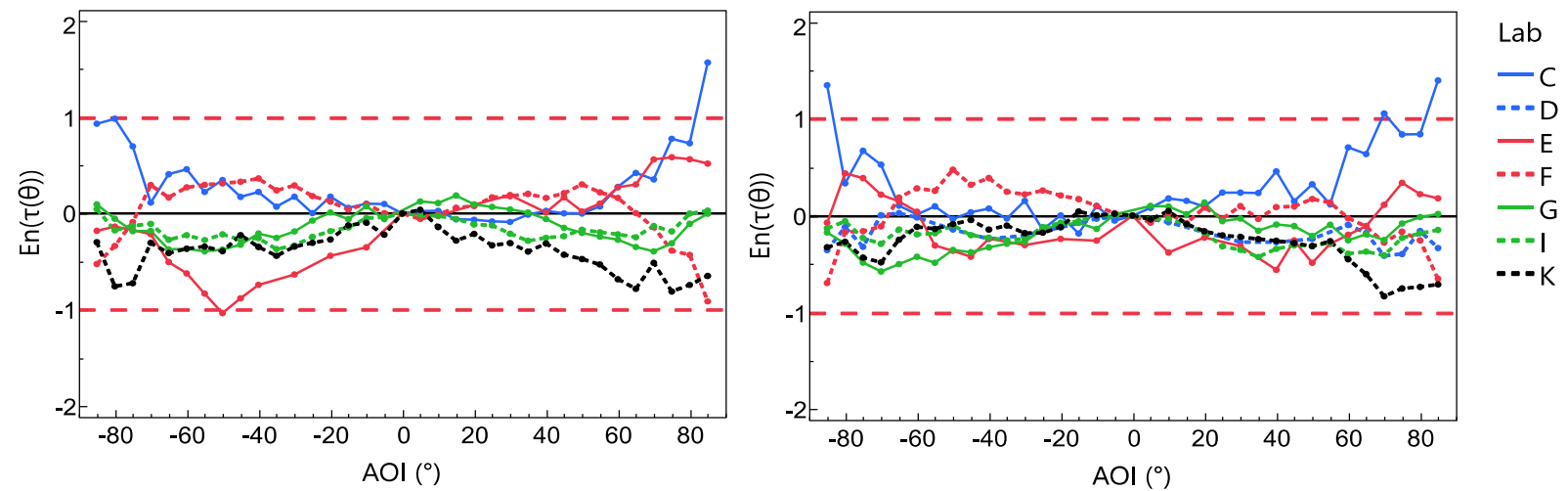

Figure 5: Proficiency of seven labs that reported measurement uncertainty per the En number statistical approach. The left graph shows results of the BSi RIE sample, the right graph shows results of the mono-Si sample.

Shown in Figure 6 are the minimum uncertainties that the remaining five labs would need at each positive AOI to be comparable to the weighted mean $X_{\text {ref, } i}$ and weighted uncertainty $U C_{r e f, i}$ of the seven labs shown in Figure 5. The results of this calculation show that at $85^{\circ}$, the measurement uncertainty that Lab J needs in order to be considered comparable is between $28 \%$ and $38 \%$, depending on the DUT. Although this uncertainty is nearly within their stated uncertainty at $85^{\circ}$ (Figure 2), there are several measurements at $\mathrm{AOI}<50^{\circ}$ that are not within their stated uncertainty. Therefore, it is likely that Lab J's test procedure needs to be reviewed and improved. Since Lab J performed the test outdoors, they should check the AOI specific calibration coefficients for the in plane pyranometer, the method for measuring the diffuse irradiance in the plane of array in addition to the accuracy of the AOI $\theta$ measurement. Figure 6 also shows the minimum uncertainties that $L a b A, B, H$ and $L$ would need in order to be comparable to the weighted mean of the seven labs shown in Figure 5. The most notable trends happen again at $85^{\circ}$ where Lab $\mathrm{H}$ would need a measurement uncertainty as high as $16 \%$ in order to be comparable to the weighted mean. This result again confirms that angular-dependent measurements at $85^{\circ}$ are challenging and therefore our recommendation is that future revisions of IEC 61853-2 state that measurements are optional where $\mathrm{AOI} \geq 85^{\circ}$. 


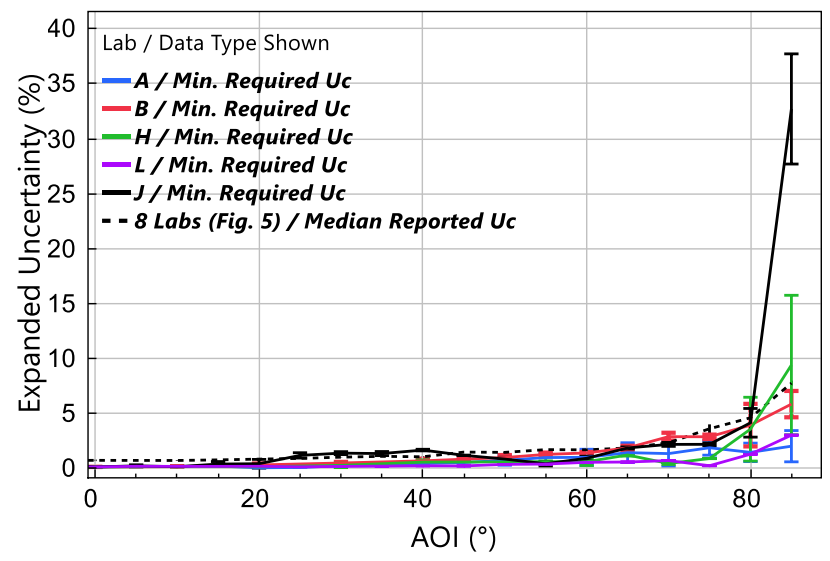

Figure 6: Minimum expanded uncertainty required for labs without measurement uncertainty to obtain $|E n| \leq 1$. The top and bottom of each range bar show the result for the mono-Si or BSi RIE sample. Only the positive angular direction is shown.
3.2 Comparison of Measured Relative Transmittance to Ray Tracing Simulations with Daidalos

In Figure 7 we show how the relative transmittance measurements for the monoSi sample compare to the curve simulated in the Daidalos ray tracing model. The results show that the Daidalos model agrees to the group median within $\pm 0.6 \%$ for $\mathrm{AOI} \leq 70^{\circ}$, within $\pm 1.4 \%$ for $\mathrm{AOI} \leq 80^{\circ}$ and at $-4.1 \%$ for an $\mathrm{AOI}=85^{\circ}$. The higher discrepancy at higher AOls is likely driven by the higher measurement uncertainty.

In Figure 8, we show the relative transmittance relative to the AM1.5G spectrum. At normal incidence, $81.3 \%$ of the

incoming photo current $I_{\text {spec }}$ is absorbed by the Si cell, while the largest losses are reflection by glass surface $4.1 \%$, reflection by other parts of the module at $5.8 \%$, absorption in the full area rear metallization of the cell $5.4 \%$, absorption in the EVA $2.2 \%$ and in the glass $0.8 \%$. There is a gradual change to $\mathrm{AOI}$ of $60^{\circ}$, where the $\mathrm{Si}$ still absorbs $76.9 \%$ of the incoming photo current $I_{\text {spec, }}$ the reflection by the glass surface is more than doubled to $9.1 \%$, while the absorption in the EVA and in the glass increase to their maximum of $2.5 \%$ and $1.0 \%$, respectively. Our simulations show that the absorption maximum for both the glass and the EVA is formed by two trends with opposite AOI dependence. On the one hand higher AOIs cause longer light path lengths in both materials and on the other hand higher AOls cause higher reflection at the glass surface, reducing the amount of light which enters both materials. For an $\mathrm{AOI}$ of $85^{\circ}$, the $\mathrm{Si}$ cell absorbs $32.8 \%$, while the glass surface reflects $61.4 \%$ of the incoming light. Please recall that the mono-Si sample has no glass anti-reflection coating, which is often used to reduce these surface reflection losses.

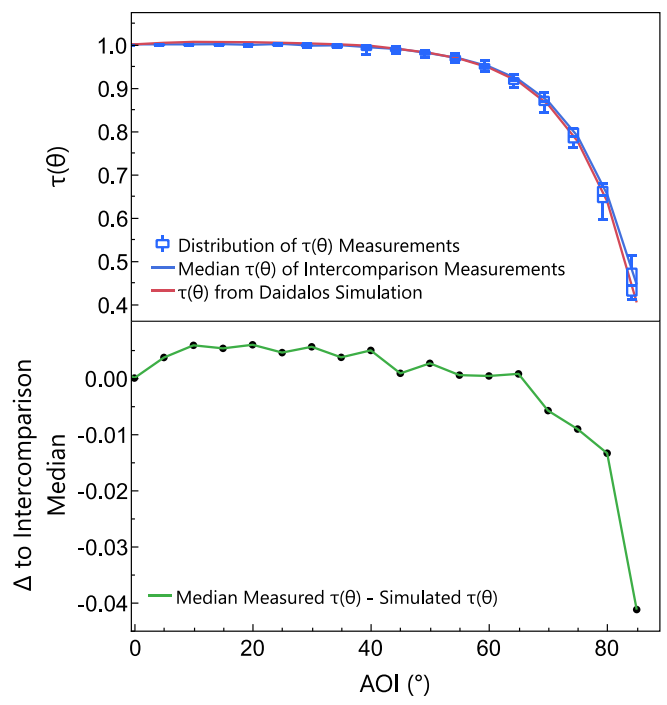

Figure 7: Comparison of measured relative transmittance to ray trace simulations of the mono-Si test sample. The blue box plots show the distribution of twelve laboratories' measurements on the mono-Si DUT at each AOI. 


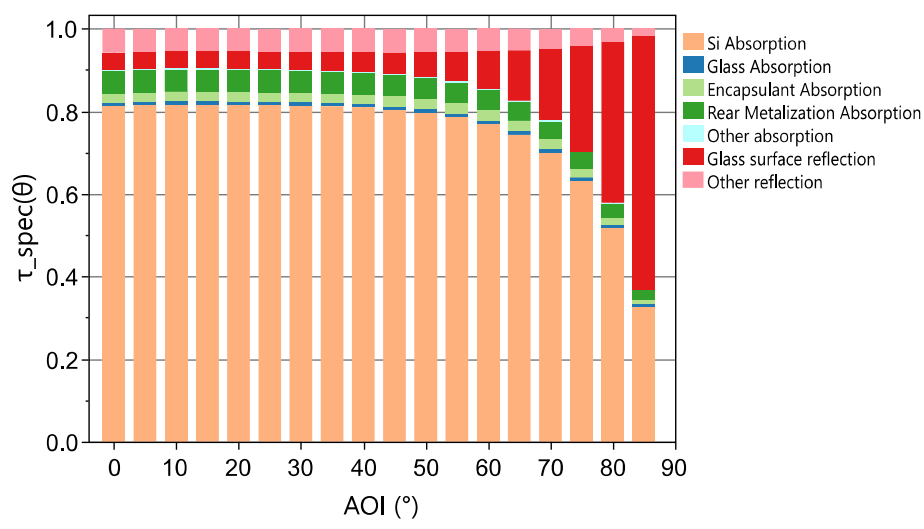

Figure 8: Ray tracing simulation results showing the angular dependence of the optical losses in the mono-Si test sample.

\subsection{Comparison of Measurement Systems: Indoor versus Outdoor}

There has been conjecture in recent years that the technical challenges encountered during outdoor testing cannot be overcome with contemporary test methods, which thus leads to speculation that angular-dependent measurements performed outdoors are unsuitable for use in PV energy modeling [15] [49]. In this section we share the experience from this intercomparison with an assessment of the angulardependent measurements from the nine indoor measurement systems and three outdoor systems.

Figure 9 shows the results from the mono-Si sample when the results are grouped by indoor and outdoor measurement systems. The black error bars indicate the full range of measurement differences as reported by the nine labs performing the test indoors. At each AOI there are three red markers that represent measurements reported by the three labs where the test was performed outdoors. When all the red markers are within the black range bars, this means that indoor measurements showed larger deviations to the intercomparison median than did the outdoor measurements.

One of the three outdoor measurements is lab J (shown in red circles as 'Outdoor 1') where many instances of non-conformity were observed previously (Figure 5). When lab J's measurements are excluded, we see that the measurements from the other two outdoor tests are either on or within the black range bars for most AOIs from $0^{\circ}$ to $85^{\circ}$. Specifically, the measurements from 'Outdoor 2 ' are always within the black range bars and those from 'Outdoor $3^{\prime}$ are inside the range bars for 10 of the 17 AOIs shown in Figure 9. Although our data set consists mostly of indoor measurements, the results shown here indicate that angular-dependent PV measurements performed outdoors are not inherently more error prone than those made indoors. It is likely that the discrepancies observed are due to the methodology employed, not the specific test location, light source, or equipment used. Figure 9 contains retest measurements from Lab $D$ and Lab $L$ where the AOI test was performed indoors; their original measurements, which we determined as non-proficient in our previous work [16], are not included in Figure 9. 


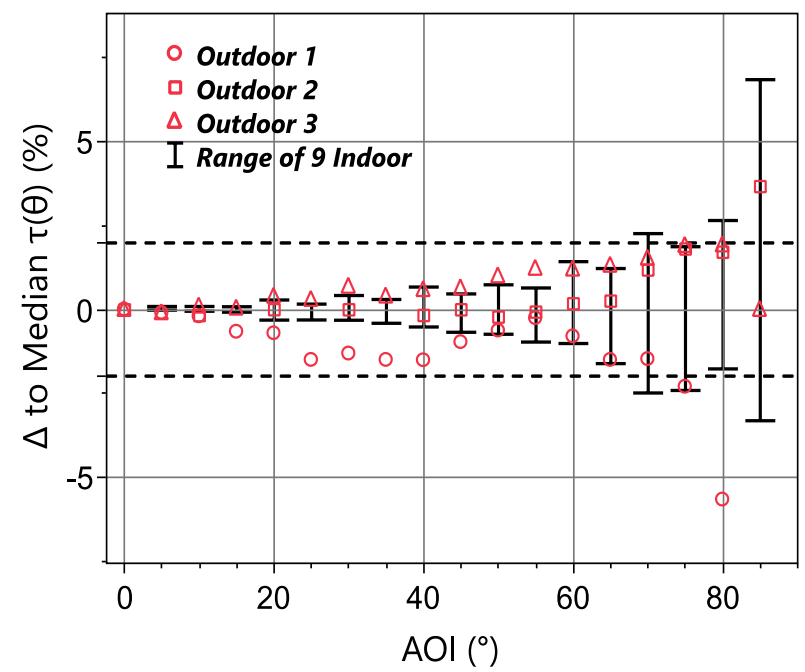

Figure 9: Comparison of indoor versus outdoor measurements made on the mono-Si sample. Dashed reference lines are drawn at $\pm 2 \%$.

\subsection{Impact of Angular-dependent Measurement Deviations on IEC 61853 Energy Rating}

Here we follow the procedures stipulated in the IEC 61853-3 standard to determine the CSER and annual energy yield of the mono-Si sample using the $a_{r}$ angular loss coefficients extracted from the measured data and from the Daidalos simulation. Table 4 shows a description of the six climates. Our calculations result in 13 CSER values per climate region (i.e. one CSER per lab plus the Daidalos simulation), where the differences in CSER values within each climate are driven by the differences in angular-dependent measurements from the participating labs.

Table 4: List of standard data sets with summaries of annual insolation, AOI between the sun and a $20^{\circ}$ tilted south oriented surface, and diffuse ratio. The mean $\mathrm{AOI}$ and diffuse ratio are calculated only during hours when the sun is above the horizon.

\begin{tabular}{|l|l|l|l|l|l|}
\hline $\begin{array}{l}\text { Data Set } \\
\text { Number }\end{array}$ & Latitude & Climate Type & $\begin{array}{l}\text { Annual global } \\
\text { insolation in in } \\
\text { plane }\left(\mathbf{k W h} \cdot \mathbf{m}^{-2} \mathbf{)}\right.\end{array}$ & $\begin{array}{l}\text { Mean } \\
\text { Annual } \\
\text { AOI } \boldsymbol{\theta}\left(^{\circ}\right)\end{array}$ & $\begin{array}{l}\text { Mean Annual } \\
\text { Diffuse Ratio }\end{array}$ \\
\hline 1 & $1^{\circ} \mathrm{S}$ & Tropical humid & 1677.7 & 50.4 & 0.71 \\
\hline 2 & $33^{\circ} 30^{\prime} \mathrm{N}$ & Subtropical arid & 2295.5 & 49.2 & 0.41 \\
\hline 3 & $33^{\circ} 22^{\prime} \mathrm{N}$ & Subtropical coastal & 1496.6 & 49.1 & 0.75 \\
\hline 4 & $56^{\circ} \mathrm{N}$ & Temperate coastal & 972.9 & 56.4 & 0.77 \\
\hline 5 & $34^{\circ} \mathrm{N}$ & High elevation & 2139.1 & 49.5 & 0.51 \\
\hline 6 & $57^{\circ} \mathrm{N}$ & Temperate continental & 1266.0 & 56.5 & 0.65 \\
\hline
\end{tabular}

Figure 10 shows that when one outlier is excluded, the range of angular-dependent measurements as reported in the intercomparison result in a $1.0 \%$ to $1.8 \%$ range in CSER values, depending on the climate. This result corresponds well with the rough estimation presented in [50] that the uncertainty of AOI measurements will lead to a $1 \%$ uncertainty in CSER. The results obtained using the Daidalos ray tracing simulations are indicated with blue diamond markers and are mostly located at the bottom of the inner quartile range. Since it was demonstrated previously that angular-dependent measurements at $85^{\circ}$ are subject to high uncertainty, Figure 10 also shows the energy rating results obtained when the curve fitting (Eq. 6 ) is done in the limited $\mathrm{AOI}$ range of $0^{\circ}$ to $80^{\circ}$. The main result from removing measurements at $85^{\circ}$ is that no outliers are observed in the energy rating outcomes, although the range of outcomes within the box plot whiskers remains largely unchanged. 

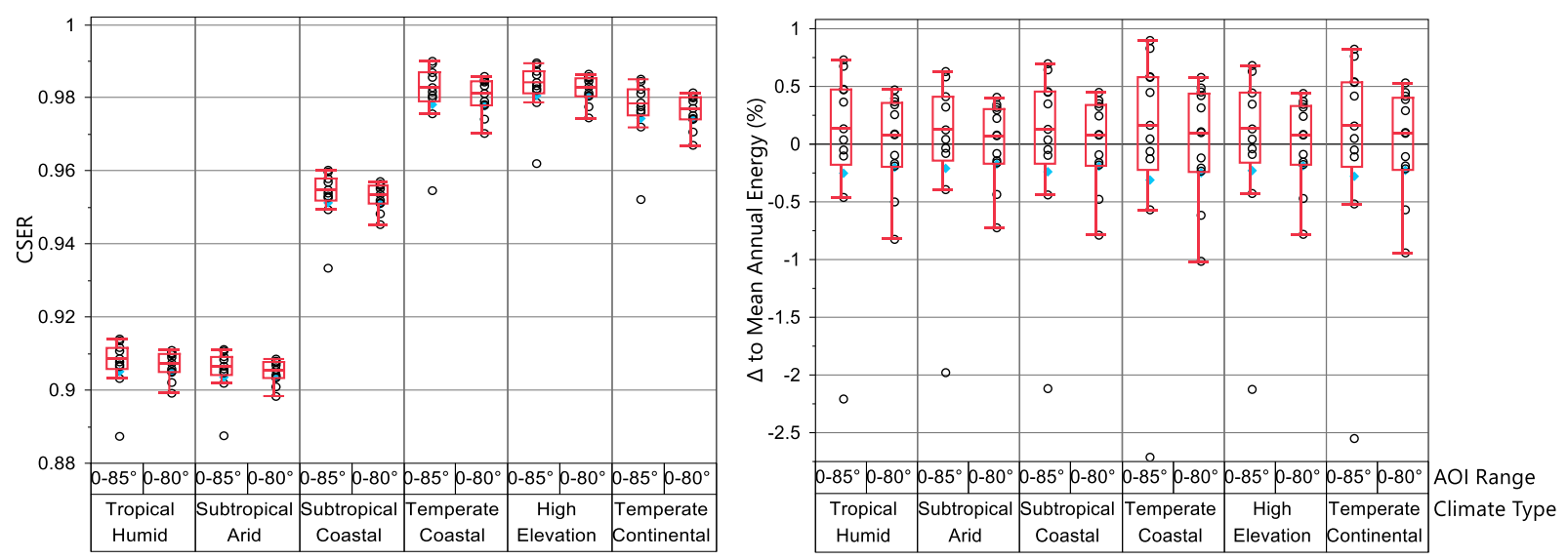

Figure 10: Results of calculating CSER with 12 participating laboratories' relative transmittance data (Left) and variability of the mean annual energy when using the 12 participating laboratories' measurements (right). Each plot shows the results when all relative transmittance measurements are used in the fitting routine $\left(0-85^{\circ}\right)$ and with $85^{\circ}$ removed $\left(0-80^{\circ}\right)$. The blue diamonds near the bottom of the inner quartile ranges show the results when CSER and annual energy are calculated using simulated relative transmittance data from Daidalos.

Figure 10 additionally shows the percentage difference to the mean annual energy yield $E$ by climate. When the one outlier is excluded, the annual energy difference can range from $1.0 \%$ to $1.5 \%$ depending on the climate. The range of CSER and energy yield values is highest for the most northern climates with high diffuse ratios and higher average AOIs (e.g. Temperature Coastal), and lowest in southern climates where lower diffuse ratios and lower average AOls are observed (e.g. Subtropical Arid). It should be emphasized that the incident angle test is one of four measured characteristics in the IEC 61853 series and the uncertainty of the other three characterizations (i.e. performance matrix, spectral responsivity, and thermal behavior) should also be considered when considering the overall uncertainty of the energy rating standard.

\subsection{Annual Angular Losses Calculated with Different Diffuse Models}

In this section we use the relative transmittance data from the intercomparison to calculate the annual angular loss (AAL) of global irradiance in the six standard climates using different approaches for calculating the diffuse radiation component $\left(D_{C o r, A O I}\right)$. We use the four calculation approaches shown in Table 3 to demonstrate the impact that the AOI fitting model and the application of the fitting model to the diffuse radiation has on global AAL. Similar to Section 3.4, only results from the mono-Si sample are shown.

Figure 11 shows the results using the Martin and Ruiz fitting model. The dotted lines show the climatespecific AAL when the closed-form approximation as prescribed in the IEC 61853-3 standard is used to apply the angular loss $a_{r}$ coefficient to the diffuse irradiance. The solid lines show the AAL when the calculation is performed by means of numerically integrating the angular-dependent losses across $1^{\circ}$ isotropic sky segments. The closed-form approximation results in $0.2 \%$ to $0.4 \%$ higher AAL across all climates. As expected, more AAL is observed in climates with higher average AOls (e.g. Temperate Coastal). Similar to the results for CSER (Figure 10), the range of global AAL is highest for the most northern climates with high diffuse ratios and higher annual average AOls, and lowest in southern climates where lower diffuse ratios and lower average AOls are observed. For example, in the case of the Temperate Coastal climate $\left(56^{\circ} \mathrm{N}\right)$, global AAL varies from $3.2 \%$ to $6.7 \%$, whereas in the Subtropical Arid climate $\left(33^{\circ} 30^{\prime} \mathrm{N}\right)$ global AAL varies from $2.1 \%$ to $4.7 \%$. 


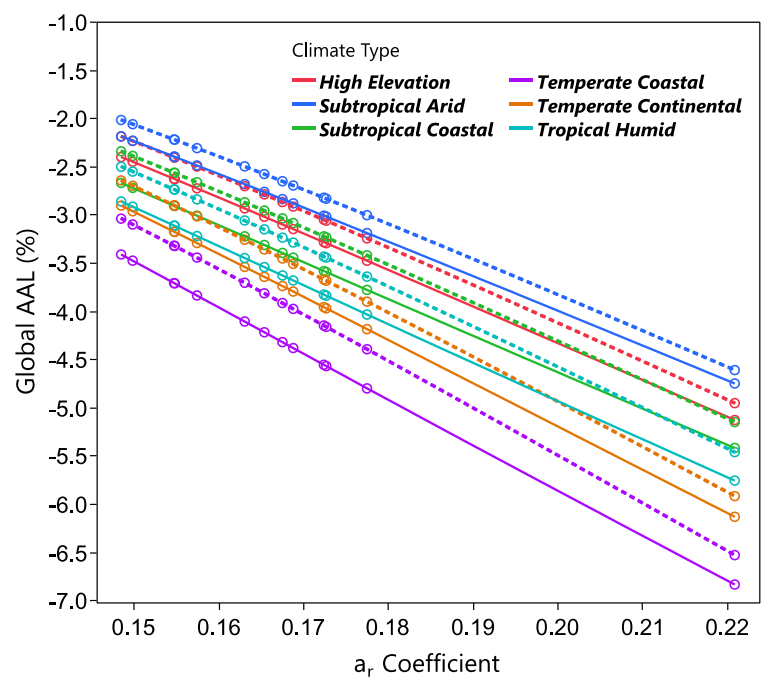

Figure 11: Annual angular losses of global irradiance using the Martin and Ruiz model. Each circle marker represents a single $a_{r}$ coefficient extracted from a participant's measurement. The dotted lines show the results using the closed-form equation to apply the angular-dependent losses and the solid lines show the results using integration to apply the losses. The $a_{r}$ coefficient extracted from the Daidalos simulation is 0.17242 .

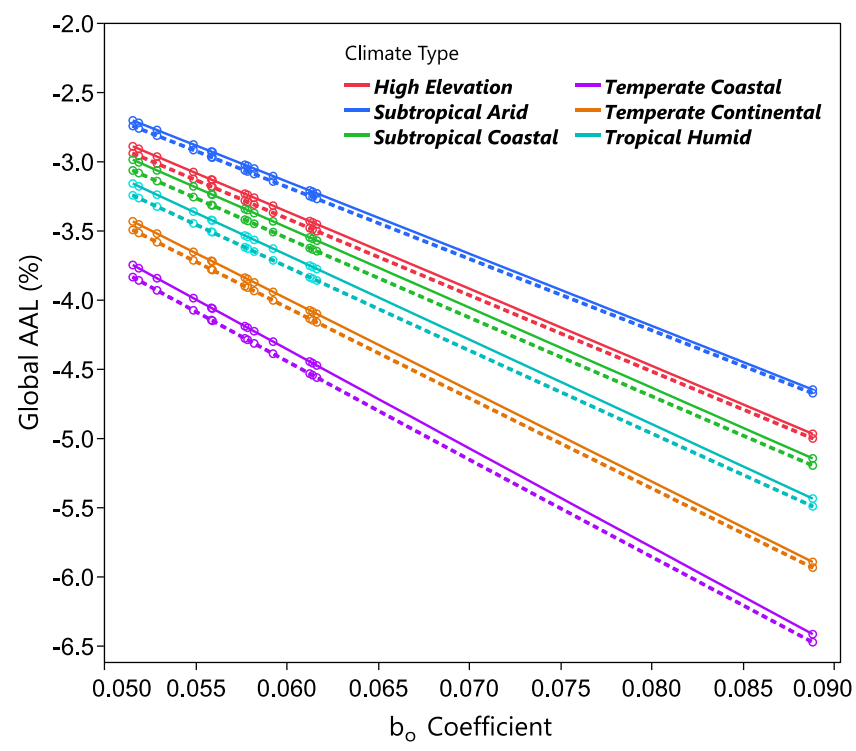

Figure 12 shows the global AAL when the ASHRAE fitting model is used to extract the $b_{o}$ angular loss coefficient from the participating laboratories' data. The dotted lines show the results when the closedform approximation in Eq. 11 is used to apply the angular-dependent losses to the diffuse radiation, and the solid lines show the results when integration is used to apply the angular-dependent losses to the diffuse radiation component. The difference in AAL as calculated by these two methods is less than $0.1 \%$ across all climates. The climate-specific AAL follow the same relative order as shown in Figure 11 , but the magnitude of the losses tends to be slightly higher $(<0.5 \%)$ when the ASHRAE fitting model is used instead 
of the Martin and Ruiz model. This could be because the ASHRAE model tends to under predict the physically measured angular-dependent losses by $2 \%$ to $3 \%$ between $40^{\circ}$ and $65^{\circ} \mathrm{AOI}$.

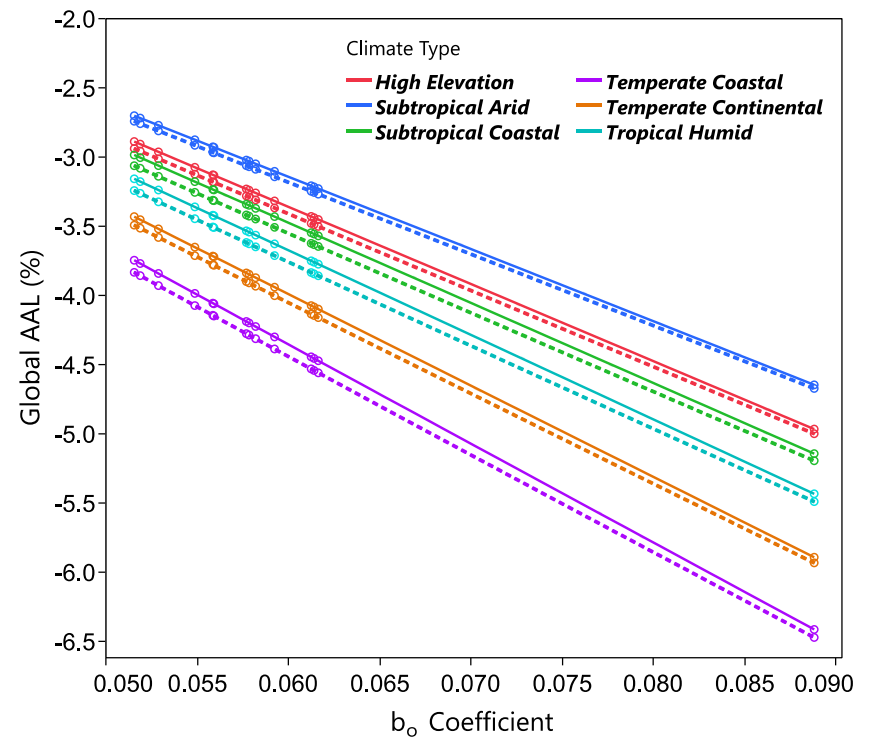

Figure 12: Annual angular losses of global irradiance using the ASHRAE model. Each circle marker represents a single $b_{o}$ coefficient extracted from a participant's measurement. The dotted lines show the results using the closed-form equation to apply the angulardependent losses and the solid lines show the results using integration to apply the losses. The $b_{0}$ coefficient extracted from the Daidalos simulation is 0.06128 .

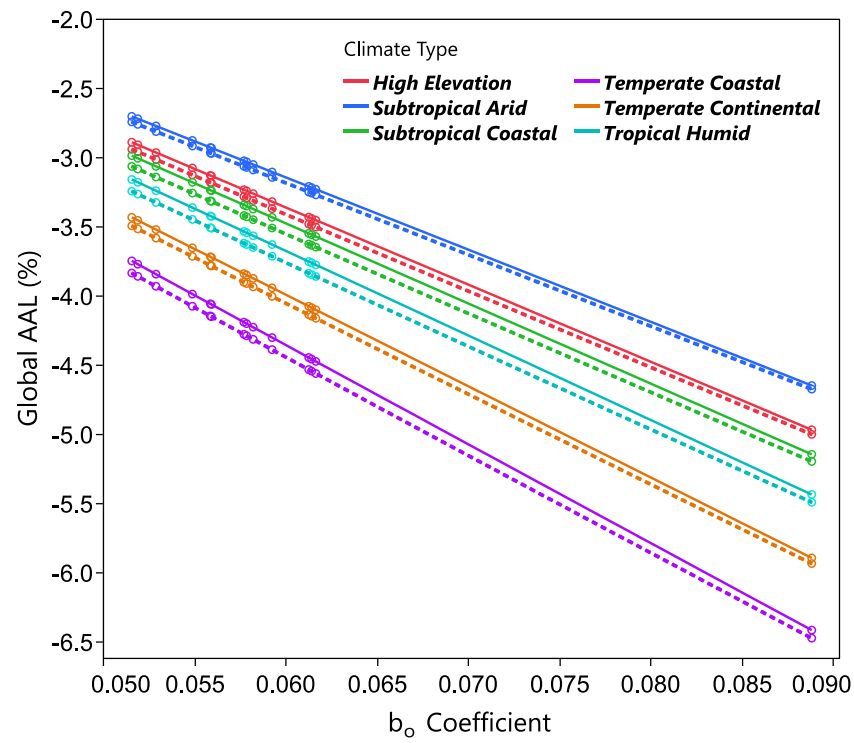

In Section 3.1 we determined that Lab J's results were not comparable to the intercomparison weighted mean and in Section 3.4 it was shown that Lab J's results were outliers when used to calculate energy rating (Figure 10). A key driver of these results is that Lab J's measurements yield the highest $a_{r}$ and $b_{o}$ angular loss coefficients out of any participant $\left(a_{r}=0.2209\right.$ and $b_{o}=0.0888$ for Lab J's mono-Si sample measurements). If Lab J's results are excluded from Figure 11 and

Figure 12, we can conclude that the range of $\mathrm{a}_{\mathrm{r}}$ and $\mathrm{b}_{\mathrm{o}}$ angular loss coefficients across the intercomparison is 0.1485 to 0.1775 and 0.0516 to 0.0617 , respectively. When Lab J's results are excluded the range of AAL 
across labs is reduced from $3.21 \%$ to $1.46 \%$ (averaged across climates) for the Martin and Ruiz model, and for the ASHRAE model the range is reduced from $2.31 \%$ to $0.68 \%$. Interesting is that the range of AAL is lower when using the ASHRAE model instead of the Martin and Ruiz. This indicates that the ASHRAE fitting model better masks the deviations in angular-dependent measurements when they are applied to PV performance modeling.

A variance components analysis can show whether the differences in the AAL primarily result from the fitting/diffuse model, the standardized climate data set, or the measured relative transmittance $\tau(\theta)$ data reported by the participating labs. We performed a variance components analysis in the JMP software package that showed that $72 \%$ of the variation in annual diffuse losses is due to the spread of angular loss coefficients, $23 \%$ of the variation is due to the climate data set, and approximately $5 \%$ of the variation is due to the fitting/diffuse model used. In other words, the variability in angular-dependent measurements across laboratories has a far greater impact on PV performance modeling results than the choice of fitting model, diffuse model or meteorological data set. This highlights the importance of accurate angular-dependent measurements in PV energy modeling as variations in $\tau(\theta)$ can cause significant changes in the annual angular losses of global irradiance. Please note that these results hold true for the fitting models, diffuse models and data sets tested, but we believe these are representative of contemporary modeling practices.

\section{Conclusions}

We have presented results from a twelve laboratory comparison of angular-dependent measurements on two encapsulated PV devices that took place from autumn 2017 to spring 2020. The proficiency of the measurements was assessed using the $E_{n}$ number method prescribed in the ISO 17043 standard, but this analysis was only applied to the measurements of seven laboratories that provided uncertainty and showed no outliers in their $\tau(\theta)$ measurements. A separate analysis was conducted for the other five labs wherein the minimum measurement uncertainty required to obtain $\left|E_{n}\right| \leq 1$ was demonstrated. The agreement of all twelve laboratories' measurements was analyzed with a simple difference between their $\tau(\theta)$ measurements and the weighted mean $X_{r e f, i}$ as calculated from seven labs with measurement uncertainty.

The $E_{n}$ number analysis revealed five total instances of unsatisfactory $\tau(\theta)$ measurements - with three such instances occurring at $85^{\circ}$ - which indicates corrective actions should be considered such as revising test procedures and uncertainty budgets. One additional suggestion is that measurements at $85^{\circ}$ could be deemed optional in future revisions of the IEC 61853-2 standard as it was demonstrated that outliers in energy rating calculations could be prevented simply by removing angular-dependent measurements at $85^{\circ}$ from the fitting procedure. The agreement in relative transmittance $\tau(\theta)$ measurements between eleven labs is within $\pm 2.0 \%$ of the weighted mean for $A O I \leq 65^{\circ}$, but from $70^{\circ}$ to $85^{\circ}$, the range of measurement differences increase rapidly from $2.5 \%$ to $23 \%$. We identified outlier measurements from one lab that performed the characterizations outdoors; in the most extreme case this lab reported measurements that were $44 \%$ low to the weighted mean at $85^{\circ}$.

We grouped the results according to indoor versus outdoor measurement methods. Although this analysis was limited in that only three of the twelve participating labs performed the test outdoors, it was shown that two of the three labs indeed had measurements that were within the range of the nine indoor measurements. Thus indicating that accuracy is not dependent on test location, but rather it is the rigor of the methodology that matters. It was shown that the variability in $\tau(\theta)$ measurements on the BSi RIE sample are $50 \%$ and $100 \%$ higher than the variability observed for the mono-Si sample at $80^{\circ}$ and $85^{\circ}$, respectively; the higher variation could be due to the nature of the BSi nanostructures. This work employed two test samples with the same glass type, but with unique cell surface textures. We suggest 
that future work on angular-dependent measurement comparisons include test samples with various structures on the glass, anti-reflective glass coatings, tandem cell technologies, and full-sized PV panels rather than single cell coupons.

The angular-dependent measurements from the participating laboratories as well as simulations from the cloud-based Daidalos ray tracing software were used as input to the IEC 61853-3 standardized procedure for calculating energy rating. When one outlier is excluded, it was found that the angular-dependent measurements from eleven participating laboratories cause a $1.0 \%$ to $1.8 \%$ range in CSER and a $1.0 \%$ to $1.5 \%$ range in annual energy yield, depending on the climate. When the CSER and energy yield results were viewed as distributions, it was shown that results from the Daidalos ray tracing simulation for all six standard climates were either within or bordering on the inner quartile range thereby demonstrating that the software is a suitable tool for simulating relative transmission curves of PV devices for use in energy rating calculations. The simulations have the benefit of describing the optical losses at each material within the PV device, which is not possible with measurements made according to IEC 61853-2. Finally, the annual angular losses (AAL) of global irradiance were analyzed using four different approaches used to apply angular-dependent losses to the diffuse radiation in six standardized climate data sets. It was shown that the measurement variability among the twelve laboratories caused the largest variation (72 $\%)$ in the AAL than did the choice of fitting or diffuse (23\%), or the meteorological data set used (5\%), which highlights the importance of accurate angular-dependent measurements for use in PV performance modeling.

\section{Acknowledgements}

We thank Dr. Werner Herrmann of TÜV Rheinland Energy GmbH for providing the spectral responsivity and multi-irradiance/temperature matrix measurements of a 60-cell crystalline Silicon module, which allowed us to perform the energy rating calculations. Part of the work made on behalf of DTU was funded by the Danish Energy Technology Development and Demonstration Program (EUDP) project number 64016-0030.

This material is based upon work supported by the U.S. Department of Energy's Office of Energy Efficiency and Renewable Energy (EERE) under Solar Energy Technologies Office (SETO) Agreement Number 34364. Sandia National Laboratories is a multi-mission laboratory managed and operated by National Technology and Engineering Solutions of Sandia LLC, a wholly owned subsidiary of Honeywell International Inc. for the U.S. Department of Energy's National Nuclear Security Administration under contract DE-NA0003525.

6 References

[1] T. W. Sjerps-Koomen EA, Anselma EA, "A simple model for PV module reflection losses under field conditions," Solar Energy, vol. 57, no. 6, pp. 421-432, 1997.

[2] N. Martin and J. M. Ruiz, "Calculation of the PV modules angular losses under field conditions by means of an analytical model," Solar Energy Materials and Solar Cells, vol. 70, no. 1, pp. 25-38, 2001.

[3] J. L. Balenzategui and F. Chenlo, "Measurement and analysis of angular response of bare and encapsulated silicon solar cells," Solar Energy Materials and Solar Cells, vol. 86, no. 1, pp. 53-83, 2005. 
[4] F. Plag, I. Kröger, T. Fey, F. Witt and S. Winter, "Angular-dependent spectral responsivity-Traceable measurements on optical losses in PV devices," Progress in Photovoltaics: Research and Applications, vol. 26, no. 8, pp. 565-578, 2018.

[5] N. Martín and J. M. Ruiz, "Annual angular reflection losses in PV modules," Progress in Photovoltaics: Research and Applications, vol. 13, no. 1, pp. 75-84, 2005.

[6] Y. S. Khoo, J. P. Singh, T. M. Walsh and A. G. Aberle, "Comparison of angular reflectance losses between PV modules with planar and textured glass under singapore outdoor conditions," IEEE Journal of Photovoltaics, vol. 4, no. 1, pp. 362-367, 2014.

[7] IEC 61853-2, "Photovoltaic ( PV ) module performance testing and energy rating - Part 2," 2016.

[8] B. Mihaylov, J. Bowers, T. Betts, R. Gottschalg, T. Krametz, R. Leidl, K. Berger, S. Zamini, N. Dekker, G. Graditi, F. Roca, M. Pellegrino, G. Flaminio, P. Pugliatti, A. Di Stefano, F. Aleo, G. Gigliucci, W. Ferrara, G. Razongles, J. Merten, A. Pozza, A. Santamaria Lancia, S. Hoffman, M. Koehl, A. Gerber, J. Noll, F. Paletta, G. Friesen and S. Dittmann, "Results of the Sophia module intercomparison part-1: stc, low irradiance conditions and temperature coefficients measurements of C-Si technologies," in 29th European Photovoltaic Solar Energy Conference and Exhibition, Amsterdam, 2014.

[9] E. Salis, D. Pavanello, M. Field, U. Kräling, F. Neuberger, K. Kiefer, C. Osterwald, S. Rummel, D. Levi, Y. Hishikawa, K. Yamagoe, H. Ohshima, M. Yoshita and H. Müllejans, "Improvements in world-wide intercomparison of PV module calibration," Solar Energy, vol. 155, pp. 1451-1461, 2017.

[10] D. Dirnberger, U. Kräling, H. Müllejans, E. Salis, K. Emery, Y. Hishikawa and K. Kiefer, "Progress in photovoltaic module calibration: Results of a worldwide intercomparison between four reference laboratories," Measurement Science and Technology, vol. 25, no. 10, 2014.

[11] J. H. Fatehi, C. Kedir, C. Tumengko, N. Riedel and J. L. R. Watts, "Results From Flash Testing At Multiple Irradiances and Temperatures Across Five PV Test Labs," 2014 PV Performance Modeling Workshop, 2014.

[12] C. Monokroussos, S. Dittmann, T. Herbrecht, H. Müllejans, E. Salis, D. Etienne, G. Friesen, J. Stang, V. Fakhfouri, N. Rebeaud and D. Pavanello, "Electrical characterization intercomparison of highefficiency c-Si modules within Asian and European laboratories," vol. 27, pp. 603-622, 2019.

[13] B. H. King, D. Riley, C. D. Robinson and L. Pratt, "Recent advancements in outdoor measurement techniques for angle of incidence effects," 2015 IEEE 42nd Photovoltaic Specialist Conference, PVSC 2015, 2015.

[14] S. Boppana, K. Passow, J. Sorensen, B. H. King and C. Robinson, "Impact of Uncertainty in IAM Measurement on Energy Predictions," 2018 IEEE 7th World Conference on Photovoltaic Energy Conversion, WCPEC 2018 - A Joint Conference of 45th IEEE PVSC, 28th PVSEC and 34th EU PVSEC, pp. 2276-2281, 2018.

[15] J. Meydbray, I. Suez and J. Webber, "Measurements Matter (White Paper)," PV Evolution Labs, Berkeley, CA, 2019.

[16] N. Riedel, A. A. S. Lancia, M. Amdemeskel, S. Thorsteinsson, P. B. Poulsen, I. Kröger, L. H. Slooff, M. J. Jansen, A. J. Carr, P. Manshanden, M. Bliss, T. Betts, I. P. Jauregui, M. E. Mayo, J. L. Balenzategui, R. Roldan, U. Kräling, G. Baarah, B. Iandolo, R. S. Davidsen, A. Thorseth, C. Dam-hansen, A. Gisele 
and R. Benatto, "Interlaboratory Comparison of Methodologies for Measuring the Angle of," 35th European Photovoltaic Solar Energy Conference and Exhibition, no. i, pp. 1034-1039, 2018.

[17] H. Holst, M. Winter, M. R. Vogt, K. Bothe, M. Kontges, R. Brendel and P. Altermatt, "Application of a New Ray Tracing Framework to the Analysis of Extended Regions in Si Solar Cell Modules," Energy Procedia, vol. 38, pp. 86-93, 2013.

[18] C. Schinke, M. R. Vogt and K. Bothe, "Optical Modeling of Photovoltaic Modules with Ray Tracing Simulations," in Photovoltaic Modeling Handbook, Wiley, 2018.

[19] W. De Soto, S. A. Klein and W. A. Beckman, "Improvement and validation of a model for photovoltaic array performance," Solar Energy, vol. 80, no. 1, pp. 78-88, 2006.

[20] D. J. Wright, "Closed-Form, Analytic Solution for Diffuse Irradiance on a Tilted, Photovoltaic Collector," IEEE Journal of Photovoltaics, vol. 9, no. 2, pp. 391-396, 2019.

[21] H. B. M. N. Al Husna, "Characterisation of Spectral and Angular Effects on Photovoltaic Modules for Energy Rating," 2018.

[22] B. Knisely, S. V. Janakeeraman, J. Kuitche and G. Tamizhmani, "Validation of IEC 61853-2 standard (Draft): Angle of incidence effect on photovoltaic modules," Conference Record of the IEEE Photovoltaic Specialists Conference, pp. 675-680, 2013.

[23] J. John, V. Rajasekar, S. Boppana, S. Tatapudi and G. Tamizhmani, "Angle of incidence effects on soiled PV modules," Reliability of Photovoltaic Cells, Modules, Components, and Systems VII, vol. 9179, no. October 2014, p. 91790D, 2014.

[24] D. Zirzow, "Improvements in CFV's Outdoor IAM Measurement Method," in Sandia PV Systems Symposium, Albuquerque, 2018.

[25] W. Herrmann and L. Rimmelspacher, "Angular Response of thin-film PV Modules," in TÜV Rheinland PV Module Forum, Cologne, 2019.

[26] W. Hermmann, M. Schweiger and L. Rimmelspacher, "Solar Simulator Measurement Proceedures for Determination of the Angular Characteristics of PV Modules," in 29th European Photovoltaic Solar Energy Conference and Exhibition, 2014.

[27] J. J. Michalsky, L. C. Harrison and W. E. Berkheiser, "Cosine response characteristics of some radiometric and photometric sensors," Solar Energy, vol. 54, no. 6, pp. 397-402, 1995.

[28] R. S. Davidsen, H. Li, A. To, X. Wang, A. Han, J. An, J. Colwell, C. Chan, A. Wenham, M. S. Schmidt, A. Boisen, O. Hansen, S. Wenham and A. Barnett, "Black silicon laser-doped selective emitter solar cell with 18.1\% efficiency," Solar Energy Materials and Solar Cells, vol. 144, pp. 740-747, 2016.

[29] B. Kafle, T. Freunda, A. Mannana, L. Clochard, E. Duffy, S. Wernera, P. Saint-Casta, M. Hofmanna, J. Rentscha and R. Preua, "Plasma-free Dry-chemical Texturing Process for High-efficiency Multicrystalline Silicon Solar Cells," Energy Procedia, vol. 92, pp. 359-368, 2016.

[30] I. Geisemeyer, N. Tucher, B. Muller, H. Steinkemper, J. Hohl-Ebinger, M. Schubert and W. Warta, "Angle Dependence of Solar Cells and Modules: The Role of Cell Texturization," IEEE Journal of Photovoltaics, vol. 7, no. 1, pp. 19-24, 2017. 
[31] ISO 17043, "Conformity assessment - General requirements for proficiency testing," 2010.

[32] T. H. Fung, T. P. D. Veeken, B. Veettil, A. Polman and M. Abbott, "Application and validity of the effective medium approximation to the optical properties of nano-textured silicon coated with a dielectric layer," Optics Express, vol. 27, no. 26, pp. 38645-38660, 2019.

[33] H. Holst, H. Schulte-Huxel, M. Winter, S. Blankemeyer, R. Witteck, M. R. Vogt, T. Booz, F. Distelrath, M. Köntges, K. Bothe and R. Brendel, "Increased Light Harvesting by Structured Cell Interconnection Ribbons: An Optical Ray Tracing Study Using a Realistic Daylight Model," Energy Procedia, vol. 92, pp. 505-514, 2016.

[34] M. R. Vogt, R. Witteck, T. Gewohn, H. Schulte-Huxel, C. Schinke, M. Köntges, K. Bothe and R. Brendel, "Boosting PV Module Efficiency Beyond the Efficiency of Its Solar Cells - A Raytracing Study with Daidalos Now Available to the Scientific Community," in 36th EU PVSEC, Marseille, 2019.

[35] ISFH, "Daidalos Cloud," [Online]. Available: https://www.daidalos-cloud.de/. [Accessed 1 May 2020].

[36] M. R. Vogt, "Development of physical models for the simulation of optical properties of solar cell modules, doctoral thesis," Gottfried Wilhelm Leibniz Universität , Hannover, Germany, 2015.

[37] D. L. King, J. A. Kratochvil and W. E. Boyson, "Measuring solar spectral and angle-of-incidence effects on photovoltaic modules and solar irradiance sensors," Conference Record of the IEEE Photovoltaic Specialists Conference, pp. 1113-1116, 1997.

[38] N. Martín and J. M. Ruiz, "A new model for PV modules angular losses under field conditions," International Journal of Solar Energy, vol. 22, no. 1, pp. 19-31, 2002.

[39] A. F. Souka and H. H. Safwat, "Determination of the optimum orientations for the double-exposure, flat-plate collector and its reflectors," Solar Energy, vol. 10, no. 4, pp. 170-174, 1966.

[40] IEC 61853-3, "Photovoltaic (PV) module performance testing and energy rating - Part 3," 2018.

[41] J. H. Fatehi and K. J. Sauer, "Modeling the incidence angle dependence of photovoltaic modules in PVsyst," 2014 IEEE 40th Photovoltaic Specialist Conference, PVSC 2014, pp. 1335-1338, 2014.

[42] W. F. Holmgren, C. W. Hansen and M. A. Mikofski, "Pvlib Python: a Python Package for Modeling Solar Energy Systems," Journal of Open Source Software, vol. 3, no. 29, p. 884, 2018.

[43] IEC 61853-4, "Standard reference climatic profiles," 2018.

[44] T. Huld, E. Salis, A. Pozza, W. Herrmann and H. Müllejans, "Photovoltaic energy rating data sets for Europe," Solar Energy, vol. 133, pp. 349-362, 2016.

[45] D. Faiman, "Assessing the outdoor operating temperature of photovoltaic modules," Progress in Photovoltaics: Research and Applications, vol. 16, no. 4, pp. 1062-7995, 2008.

[46] M. Vogt, S. Riechelmann, A. Gracia-Amillo, A. Driesse, A. Kokka, K. Maham, P. Kärhä, R. Kenny, C. Schinke, K. Bothe, J. Blakesley, E. Music, F. Plag, G. Friesen, G. Corbellini, N. Riedel-Lyngskær, R. Valckenborg, M. Schweiger and W. Herrmann, "Interlaboratory Comparison of the PV Module Energy Rating Standard IEC 61853-3," in 37th European Photovoltaic Solar Energy Conference and Exhibition, 2020. 
[47] B. Marion, "Numerical method for angle-of-incidence correction factors for diffuse radiation incident photovoltaic modules," Solar Energy, vol. 147, pp. 344-348, 2017.

[48] F. Plag, I. Kröger, S. Riechelmann and S. Winter, "Multidimensional model to correct PV device performance measurements taken under diffuse irradiation to reference conditions," Solar Energy, no. 174, pp. 431-444, 2018.

[49] PVsyst, "How to Determine the IAM Profile," [Online]. Available: https://forum.pvsyst.com/viewtopic.php?t=2690. [Accessed 24 March 2020].

[50] D. Dirnberger, B. Muller and C. Reise, "PV module energy rating: opportunities and limitations," Progress in Photovoltaics, vol. 23, pp. 1754-1770, 2015. 
Appendix I

Table 5: Participating laboratories and details of their measurement systems used for measuring the angle of incidence response in the intercomparison.

\begin{tabular}{|c|c|c|c|}
\hline Lab & $\begin{array}{l}\text { Institution } \\
\text { description }\end{array}$ & $\begin{array}{l}\text { Rotation } \\
\text { stage AOI } \\
\text { range and } \\
\text { control }\end{array}$ & $\begin{array}{l}\text { Additional details regarding the measurement system and the } \\
\text { methodology used }\end{array}$ \\
\hline CENER & $\begin{array}{l}\text { National lab with } \\
\text { ISO } 17025 \\
\text { accreditation. } \\
\text { Not accredited to } \\
\text { do IEC 61853-2 } \\
\text { Incident Angle Test. }\end{array}$ & $\begin{array}{l}2 \text {-axis, } 0^{\circ} \text { to } \\
90^{\circ} \\
\text { Automated }\end{array}$ & $\begin{array}{l}\text { Outdoors in natural sunlight on dual axis tracker. Plane of array } \\
\text { diffuse calculated from global and beam measurements. } \\
\text { Reported values are not the result of averaged measurements. } \\
\text { All } I_{s c} \text { measurements are corrected to a common temperature } \\
\text { using measurements from a thermocouple attached to the back } \\
\text { of the DUT. }\end{array}$ \\
\hline CFV Labs & $\begin{array}{l}\text { Commercial test lab } \\
\text { with ISO } 17025 \\
\text { Accredited. Is } \\
\text { accredited to do } \\
\text { Incident Angle Test } \\
\text { (IEC 61853-2). }\end{array}$ & $\begin{array}{l}2 \text {-axis, } 0^{\circ} \text { to } \\
90^{\circ} \\
\text { Automated }\end{array}$ & $\begin{array}{l}\text { Outdoors in natural sunlight on dual axis tracker. Plane of array } \\
\text { diffuse calculated from global and beam measurements. Global } \\
\text { pyranometer measurements use individual AOI calibration } \\
\text { coefficients. DUTs are kept in the open-circuit state between ISC } \\
\text { measurements. Reference modules used for spectral } \\
\text { corrections. Tracker dwells for } 3 \text { minutes at each AOI to allow } \\
\text { DUTs and irradiance sensors to stabilize. Reported values are } \\
\text { based on the average of at least } 5 I_{s c} \text { measurements at each AOI. }\end{array}$ \\
\hline CIEMAT & $\begin{array}{l}\text { Public R\&D } \\
\text { company. Not ISO } \\
17025 \text { accredited. }\end{array}$ & $\begin{array}{l}\text { 1-axis, }-90^{\circ} \\
\text { to } 90^{\circ}, \\
\text { Automated }\end{array}$ & $\begin{array}{l}\text { Pasan flasher with broadband Xe arc lamp (class AAA). Lamp } \\
\text { distance to DUT }=4.5 \mathrm{~m} \text {. Flash tunnel with large windows acting } \\
\text { as optical diaphragms. Maximum full-area DUT size for AOI } \\
\text { measurements }=0.5 \times 0.5 \mathrm{~m} \text { (mounting plane area). Reported } \\
\text { values are based on the average of } 9 I_{s c} \text { measurements. All } I_{s C} \\
\text { measurements are corrected to } 25^{\circ} \mathrm{C} \text {. Irradiance stability } \\
\text { correction applied to } I_{s c} \text { based on reference cell measurements } \\
\text { at normal incidence. }\end{array}$ \\
\hline CREST & $\begin{array}{l}\text { University with ISO } \\
17025 \\
\text { accreditation. Not } \\
\text { accredited to do IEC } \\
61853-2 \quad \text { Incident } \\
\text { Angle Test. }\end{array}$ & $\begin{array}{l}\text { 1-axis, }-90^{\circ} \\
\text { to }+90^{\circ} \\
\text { Automated }\end{array}$ & $\begin{array}{l}\text { Pasan } 3 \mathrm{~b} \text { flasher with broadband Xe arc lamp (class AAA). Lamp } \\
\text { distance to DUT }=7.5 \mathrm{~m} \text {. To measure the negative direction the } \\
\text { module was mounted the other way around and then measured } \\
\text { again. This method reduces the stray light the DUT is exposed } \\
\text { to. No temperature correction applied as it was considered a } \\
\text { minor contribution to overall uncertainty. Irradiance stability } \\
\text { correction applied to } I_{s C} \text { based on reference cell measurements } \\
\text { at normal incidence. Maximum full-area DUT size for AOI } \\
\text { measurements }=1.7 \mathrm{~m} \times 1.1 \mathrm{~m} \text { (i.e. mounting table area). When } \\
\text { the DUT is a PV module, the non-destructive partial shade } \\
\text { method described in [26] is used to examine a subpart of the } \\
\text { DUT. }\end{array}$ \\
\hline DTU & $\begin{array}{l}\text { University. Not ISO } \\
17025 \text { accredited. }\end{array}$ & $\begin{array}{l}\text { 1-axis, }-90^{\circ} \\
\text { to }+90^{\circ} \\
\text { Automated }\end{array}$ & $\begin{array}{l}\text { Energetiq (EQ-99FCX) broadband laser driven light source } \\
\text { collimated using an off axis parabolic mirror. Active area of test } \\
\text { samples partially illuminated. All ISC measurements are } \\
\text { corrected to } 25^{\circ} \mathrm{C} \text {. Reported values at each AOI result from the }\end{array}$ \\
\hline
\end{tabular}




\begin{tabular}{|c|c|c|c|}
\hline & & & $\begin{array}{l}\text { average of } 5 I_{s c} \text { measurements and the average of } 3 \mathrm{AOI}(\theta) \\
\text { measurements. }\end{array}$ \\
\hline $\begin{array}{l}\text { Fraunhofer } \\
\text { ISE }\end{array}$ & $\begin{array}{l}\text { Research institute } \\
\text { with ISO } 17025 \\
\text { accreditation. Not } \\
\text { accredited to do IEC } \\
61853-2 \text { Incident } \\
\text { Angle Test. }\end{array}$ & $\begin{array}{l}\text { 1-axis, }-90^{\circ} \\
\text { to }+90^{\circ}, \\
\text { Manual }\end{array}$ & $\begin{array}{l}\text { Pasan } 3 \mathrm{~b} \text { flasher with broadband Xe arc lamp (class AAA). Lamp } \\
\text { distance to DUT }=8.0 \mathrm{~m} \text {. Measurements made in } 10^{\circ} \text { steps } \\
\text { between } 0^{\circ} \text { and } 50^{\circ} \text {, and in } 5^{\circ} \text { steps between } 50^{\circ} \text { and } 85^{\circ} \text {. Values } \\
\text { reported are based on single } I_{S C} \text { measurements except at } 0^{\circ}(3 \\
I_{S c} \text { measurements averaged) and } 70^{\circ}\left(2 I_{S C} \text { measurements }\right. \\
\text { averaged) to establish repeatability. All } I_{S C} \text { measurements } \\
\text { acquired with DUT at } 25^{\circ} \mathrm{C} \pm 1.0^{\circ} \mathrm{C} \text { and normal incidence } \\
\text { irradiance } 1000 \mathrm{~W} / \mathrm{m}^{2} \pm 2 \mathrm{~W} / \mathrm{m}^{2} \text {. All } I_{S C} \text { measurements are } \\
\text { corrected to } 25^{\circ} \mathrm{C} \text {. Irradiance stability correction applied to } I_{S C} \\
\text { based on WPVS reference cell measurements at normal } \\
\text { incidence. Geometrical factor correction for the } 6 \mathrm{~mm} \text { out-of- } \\
\text { axis rotation in test set-up. No spectral mismatch corrections } \\
\text { applied. }\end{array}$ \\
\hline PVEL & $\begin{array}{l}\text { Commercial lab } \\
\text { with ISO } 17025 \\
\text { accreditation. Not } \\
\text { accredited to do IEC } \\
61853-2 \text { Incident } \\
\text { Angle Test. }\end{array}$ & $\begin{array}{l}0^{\circ} \text { to } 90^{\circ}, \\
\text { Automated }\end{array}$ & $\begin{array}{l}\text { Collimated pulsed LED light source with steady-state bias light. } \\
\text { The distance between the light source and the DUT is } \\
\text { approximately } 18 \text { meters. Lock-in amplifiers used to isolate } \\
\text { signal from collimated light. Isc at each AOI is measured at } 512 \\
\text { samples/second for } 30 \text { seconds. Thus, reported values at each } \\
\text { AOI are the average of nearly } 15,000 \text { data points. Irradiance } \\
\text { stability correction applied to Isc based on irradiance } \\
\text { measurements at normal incidence. }\end{array}$ \\
\hline PTB & $\begin{array}{l}\text { National lab with } \\
\text { ISO } \quad 17025 \\
\text { accreditation. Not } \\
\text { accredited to do IEC } \\
61853-2 \quad \text { Incident } \\
\text { Angle Test. }\end{array}$ & $\begin{array}{l}\text { 2-axis, }-90^{\circ} \\
\text { to }+90^{\circ} \text {, } \\
\text { Automated } \\
\text {, Azimuthal } \\
\text { rotation of } \\
\text { DUT } \\
\text { possible. }\end{array}$ & $\begin{array}{l}\text { Angular-dependent measurement of the differential spectral } \\
\text { responsivity using a tuneable laser system with broadband bias } \\
\text { lamps. Diffuse light from the ambience has no impact since Lock- } \\
\text { In technique is applied. Reported values at each AOI are the } \\
\text { average of } 25 \text { measurements. Divergence of the light source is < } \\
5^{\circ} \text { (uncertainty related to divergence is considered). }\end{array}$ \\
\hline RETC & $\begin{array}{l}\text { Commercial lab } \\
\text { with ISO } 17025 \\
\text { accreditation. } \\
\text { Accredited to do } \\
\text { IEC } 61853-2 \\
\text { Incident Angle Test. }\end{array}$ & $\begin{array}{l}\text { 1-axis, }-90^{\circ} \\
\text { to }+90^{\circ}, \\
\text { Manual }\end{array}$ & $\begin{array}{l}\text { Pasan 3b with broadband Xe arc lamp (class AAA). No } \\
\text { methodological details provided. }\end{array}$ \\
\hline Sandia Labs & $\begin{array}{l}\text { Test lab. Not ISO } \\
17025 \text { accredited. }\end{array}$ & $\begin{array}{l}0^{\circ} \text { to } 90^{\circ}, \\
\text { Automated }\end{array}$ & $\begin{array}{l}\text { Outdoors in natural sunlight on dual axis tracker. Plane of array } \\
\text { diffuse directly measured using the tracker's ability to maintain } \\
\text { constant azimuth with the sun's position. Values reported were } \\
\text { based on } 3 \text { days of clear sky measurements. Thus, reported } \\
\text { values at each AOI are the average of approximately } 100 \\
\text { measurements. All Isc measurements are corrected to a } \\
\text { common temperature using measurements from a resistance } \\
\text { temperature detector (RTD) attached to the back of the DUT. }\end{array}$ \\
\hline
\end{tabular}




\begin{tabular}{|c|l|l|l|}
\hline SUPSI & $\begin{array}{l}\text { Commercial lab } \\
\text { with ISO 17025 } \\
\text { accreditation. Not } \\
\text { accredited to do IEC } \\
61853-2 \text { Incident } \\
\text { Angle Test. }\end{array}$ & $\begin{array}{l}\text { 1-axis, }-90^{\circ} \\
\text { Manual }\end{array}$ & $\begin{array}{l}\text { Pasan flasher with broadband Xe arc lamp (class AAA). Distance } \\
\text { between the lamp and center of the rotational axis of DUT }=7.2 \\
\text { m. All } I_{s c} \text { measurements acquired with DUT at } 25^{\circ} \mathrm{C} \pm 0.5^{\circ} \mathrm{C} \text { and } \\
\text { normal incidence irradiance } 1000 \mathrm{~W} / \mathrm{m}^{2} \pm 20 \mathrm{~W} / \mathrm{m}^{2}, \text { thus no } \\
\text { additional corrections were applied. Reported values at each } \\
\text { AOI result from the average of } 3 I_{s c} \text { measurements. }\end{array}$ \\
\hline TNO & $\begin{array}{l}\text { R\&D lab. Not ISO } \\
17025 \text { accredited. }\end{array}$ & $\begin{array}{l}1 \text {-axis, }-90^{\circ} \\
\text { to }+90^{\circ}, \\
\text { Manual }\end{array}$ & $\begin{array}{l}\text { Pasan flasher with broadband Xe arc lamp (class AAA). Flash } \\
\text { tunnel length }=8 \mathrm{~m} \text {. Suppression of stray light with diaphragms, } \\
\text { black paint, and black coverings. Maximum DUT size for AOI test } \\
=160 \times 160 \mathrm{~mm} \text {. All Isc measurements are corrected to } 25^{\circ} \mathrm{C} . \\
\text { Irradiance stability correction applied to ISC based on } \\
\text { measurements at normal incidence. }\end{array}$ \\
\hline
\end{tabular}

Appendix II: Supplemental Data

The relative transmittance data reported by the laboratories can be found in DTU's open access repository https://doi.org/10.11583/DTU.12613325.v1. This data set can assist researchers in developing and validating new models that describe the angular-dependent behavior of encapsulated PV devices. 